\title{
ӘInversion Climatology in High-Production Agricultural Regions of Missouri and Implications for Pesticide Applications
}

\author{
MANDY D. BISH \\ Division of Plant Sciences, University of Missouri, Columbia, Missouri \\ PATRICK E. GUINAN \\ School of Natural Resources, University of Missouri, Columbia, Missouri \\ KEVIN W. BRADLEY \\ Division of Plant Sciences, University of Missouri, Columbia, Missouri
}

(Manuscript received 2 October 2018, in final form 24 May 2019)

\begin{abstract}
Most pesticides applied in the United States have labels that include language prohibiting application during temperature inversions. This restriction, which is well known and is followed by aerial pesticide applicators, has more recently become a focus for ground pesticide applicators. This is partially due to the recent introduction of genetically engineered soybean and cotton with tolerance to dicamba herbicide. Dicamba has been utilized for more than 50 years to control weeds in grain crops, such as corn. In 2017, dicamba was approved for use in dicamba-tolerant soybean and cotton. In 2017 and 2018, dicamba movement onto nontarget plants was substantial. As based on patterns of injury to nontolerant crops and time of applications, some of which occurred during the evening, inversions were likely contributors to off-target movement. Historically, most research on surface temperature inversions and pesticides focused on aerial applications. Research presented here focused on development of inversion profiles at atmospheric heights relevant to ground applications, which typically occur $46-107 \mathrm{~cm}$ above ground level (AGL). During the 2015-17 soybean growing seasons, data were collected at three heights AGL $(46,168$, and $305 \mathrm{~cm})$ in three soybeanproducing regions of Missouri to characterize inversions. Over 600 inversions were characterized; all were nocturnal in nature. Inversions typically lasted overnight at two locations; duration varied at the third. The largest temperature difference recorded was $6^{\circ} \mathrm{C}$. This research has resulted in real-time inversion monitoring that is available online to applicators (http://agebb.missouri.edu/weather/realTime/maps/ index.php\#temp_inversion), and the data generated can be utilized to improve accuracy of low-level inversion forecasting models.
\end{abstract}

\section{Introduction}

Most pesticides applied in the United States have labels that include language prohibiting applications during surface temperature inversions. Similar to challenges associated with pollution dispersion, valley atmosphere transport, and plumes from forest fires, inversions are likely to impact dispersion of pesticide droplets during application (Allwine et al. 1997; Ferguson et al. 2003;

๑ Denotes content that is immediately available upon publication as open access.

Corresponding author: Mandy Bish, bishm@missouri.edu
Finn et al. 2008; Enz et al. 2017; Janhall 2015). Much of the previous research pertaining to the influence of surface temperature inversions on agriculture crop production in the United States has been focused at heights relevant to aerial pesticide applications, which occur between 2.4 and $3.7 \mathrm{~m}$ above the intended targets (Bird et al. 1996; https://pesticidestewardship.org/pesticidedrift/aerial-application/). However, in the last three years, information regarding inversions relevant to ground pesticide applications, which typically occur at heights of approximately $46-107 \mathrm{~cm}$ above targets, has gained interest in the agriculture community of the Midwestern and midsouthern United States. This interest has been driven primarily by applications of dicamba herbicide 
and subsequent movement of the herbicide from target plants to unintended, sensitive plants.

Dicamba was first legally utilized in soybean and cotton in the United States in 2017 following the commercial introduction of soybean and cotton genetically engineered to tolerate the herbicide (Behrens et al. 2007). Labels prohibit aerial application of dicamba to these crops (EPA 2017a,b). The chemical is unique in that the dosage required to injure sensitive plants is much lower than other commonly used herbicides (Al-Khatib et al. 1993; Al-Khatib and Peterson 1999; Behrens et al. 2007; Everitt and Keeling 2009; Solomon and Bradley 2014). Thus it stands to reason that a much lower volume of dicamba herbicide suspended during an inversion could result in injury to sensitive plants when compared with the volume that would be required of other commonly used herbicides. Unfortunately, in 2017 and 2018 widespread issues of dicamba movement and injury to nontarget plants were reported in high soybean production areas of the United States. Collectively, state departments of agriculture reported over 4000 dicamba-related investigations in the two years (Bradley 2017a, 2018). In Missouri alone, the number of dicamba-related investigations conducted in 2017 by the Missouri Department of Agriculture (MDA) was an increase of over $700 \%$ relative to the usual total number of chemical complaints filed with MDA annually (MDA staff 2017, personal communication). Similar situations occurred in Arkansas, Indiana, Illinois, and Tennessee during the 2017 and 2018 growing seasons.

Many factors were thought to contribute to off-target dicamba movement. From patterns of injury to nontolerant crops, a subset of the injury resembled physical drift, in which injury symptoms were more severe on one side of the field nearest dicamba application and lessened across the field as one moves farther from the source (Akesson and Yates 1964; Jones et al. 2019). Physical drift has been well characterized (Yates et al. 1967; Alves et al. 2017; Thistle et al. 2017), and both aerial and ground pesticide applicators have familiarity with causes of physical drift such as applications made during windy conditions, use of the wrong types of spray nozzles, and omission of a drift-reduction agent (VanGessel and Johnson 2005; Pfleeger et al. 2006; Creech et al. 2015; Bish and Bradley 2017). However, in some dicamba-injured fields, the pattern of injury was inconsistent with physical drift. Fields that were not sprayed with dicamba had consistent dicamba-injury symptoms across the entire area. Investigations into the timing of dicamba applications suggested that many applications were conducted in evening hours, when wind speeds were reduced and less problematic for physical drift concerns. Spraying dicamba at night to avoid high

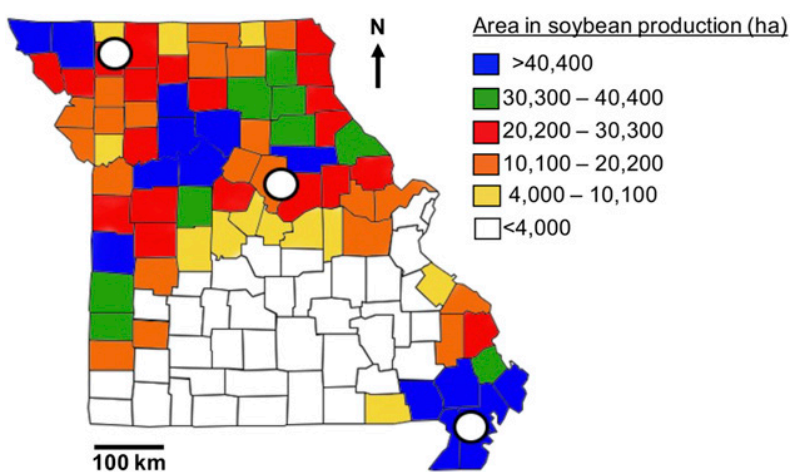

FIG. 1. Missouri soybean production by county: map of harvested soybean area from Missouri Agriculture Statistics Service data. The white circles indicate sites that were utilized for inversion monitoring over the 3-yr study.

wind speeds, a general lack of understanding about temperature inversions or conditions associated with inversions, and dicamba-injury patterns in some fields suggest that spraying dicamba during inversion conditions was likely one contributor to off-target movement (Bish and Bradley 2017; Bradley 2017b).

Much research has been conducted to understand nocturnal inversions in the continental, United States. Some of the initial studies carried out to characterize frequencies and duration of inversions in the Midwestern United States utilized historical radiosonde data or realtime air temperature data to determine frequencies and durations of inversions (Hosler 1961; Baker et al. 1969; Holzworth 1967). Results from both of these studies indicated that nocturnal inversions were common in the Midwestern United States and the findings from Baker et al. (1969) revealed the number of inversions was dependent on what height above ground level (AGL) the air temperatures were being recorded (Baker et al. 1969). More recent inversion studies have focused on characterizing conditions associated with formation and dissipation of the nocturnal boundary layer (NBL; Stull 1988). Locations and dates utilized for these types of studies were selected to maximize the number of intensive observation periods (IOPs) for data collection, analysis, and NBL characterization. The CASES-99 study was conducted in southeastern Kansas in October of 1999 and included instrumentation or expertise from 31 laboratories, which resulted in substantial amounts of data that have continued to be mined (Poulos et al. 2002; Sun et al. 2012; Van de Wiel et al. 2017). One preliminary finding from CASES-99 was the observation that temperature fluctuations in short vertical distances occur frequently in the NBL. This observation on temperature fluctuations, combined with Baker et al.'s early observation of variation in inversion frequency depending on height AGL, 

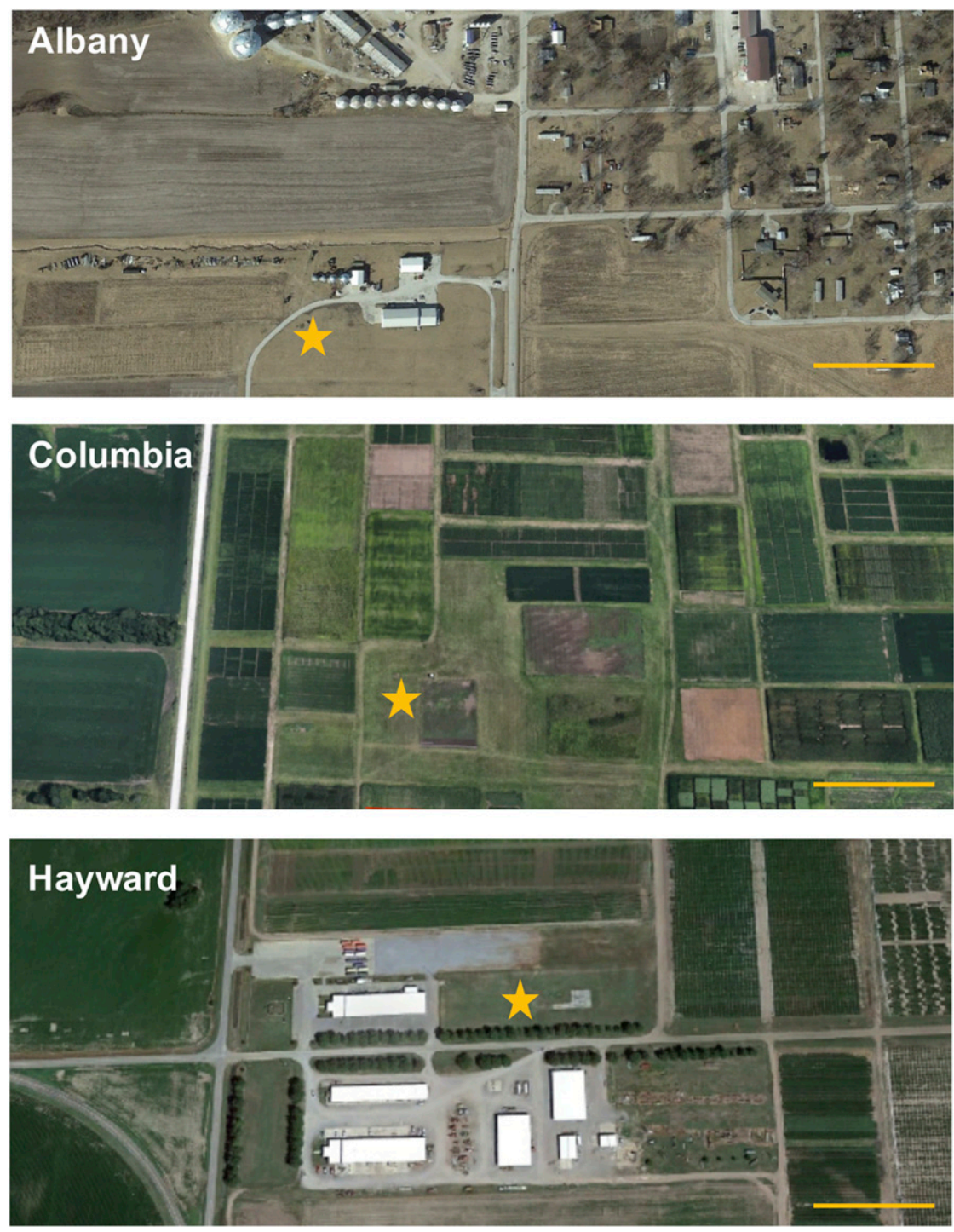

FIG. 2. Topography and points of possible obstruction at each location. The gold bar in the bottom-right corners represents $100 \mathrm{~m}$. The gold star marks the location of the weather station. (The maps were generated using Google Earth.)

provides support for the need to investigate inversions at heights that would be relevant to ground pesticide applications (Baker et al. 1969).

Variations in microclimates should also be considered when studying inversions and ground pesticide applications. Many of the cropping areas in the Midwestern and midsouthern United States have been established in large and mostly open regions (USDA 1981). However, there are differences in topography, physical wind barriers, and elevation that may vary from region to region and influence formation of the NBL. The extensive Oklahoma Mesonet system has been able to capture one example of this by recording inversions at atmospheric heights of 1.5 and $9 \mathrm{~m}$ at 100 locations within the state
(Hunt et al. 2007; McPherson et al. 2007). The El Reno Oklahoma Mesonet site (ELRE) has flat and open ground and minimal obstructions, and as a result of that topography it has unexpectedly registered some of the strongest inversions in the network. Further investigation led to the discovery that more rapid in situ cooling of the 1.5-m air temperature than the 9-m air temperature was the difference when compared with other stations (Hunt et al. 2007).

The objective of this work is to build upon the previous research pertaining to temperature inversions in the Midwest cropping region by characterizing inversions at heights relevant to ground pesticide applicators within soybean-growing geographies. The study was 

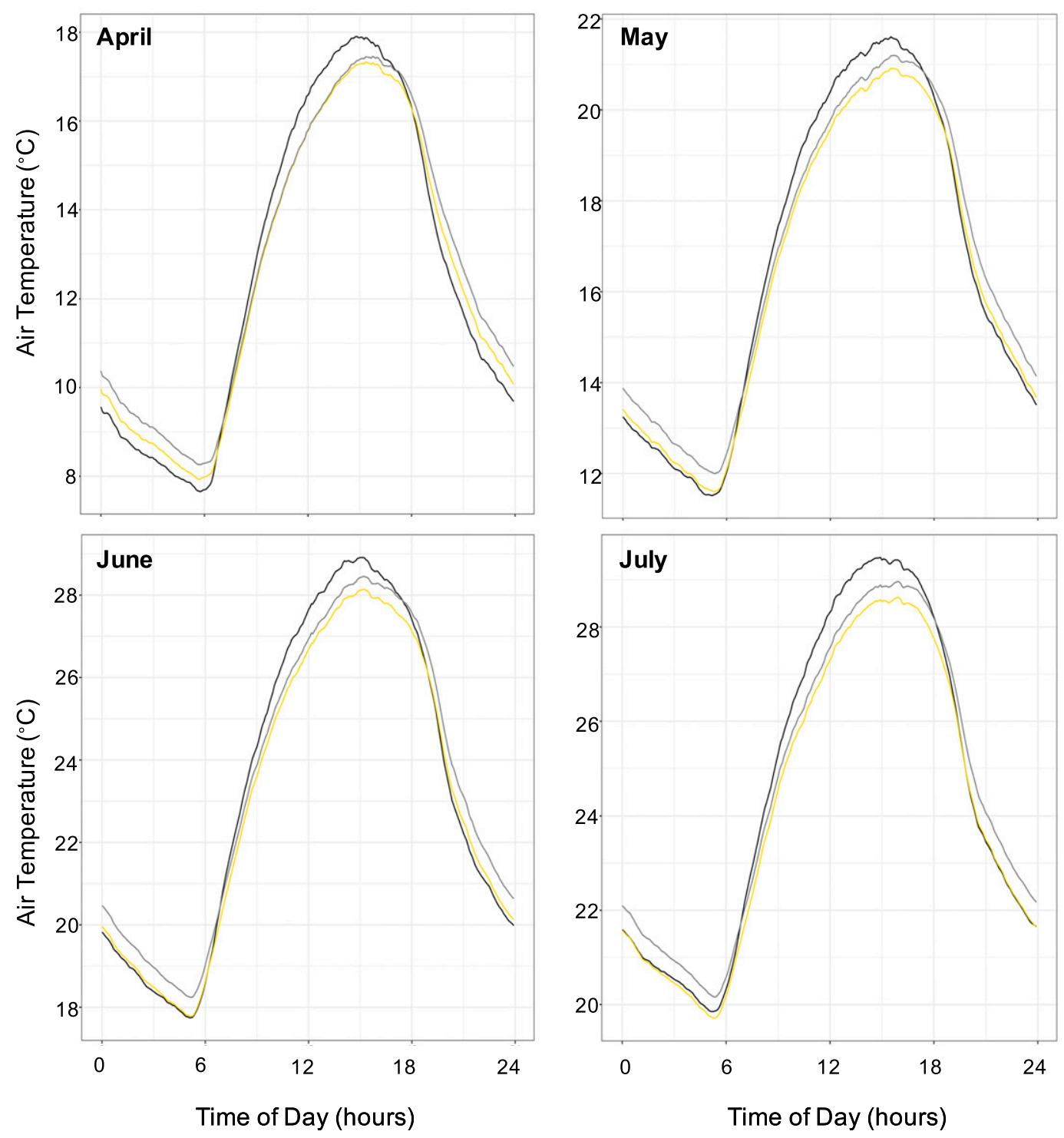

FIG. 3. Daily air temperature trends in Albany from 2015 to 2017 show that inverted temperatures are typical during the evenings in the growing season. Black, gold, and gray lines indicate the temperature at 46, 168, and $305 \mathrm{~cm}$, respectively.

conducted in three distinct soybean-growing geographies in Missouri (Fig. 1), utilized real-time data measurements, and was conducted over the common soybean growing season months of April, May, June, and July from 2015 to 2017. Preliminary data generated from this research have been utilized by state governments in Missouri and Tennessee to restrict application timing for dicamba applications, have been incorporated into mandated training for dicamba applications, and have led to the establishment of a "Temperature Inversion Potential" (TIPs) website (http://agebb.missouri.edu/ weather/realTime/maps/index.php\#temp_inversion) for pesticide applicators to access real-time inversion potentials across Missouri. Long-term forecasting information would be most useful to agricultural producers for planning purposes, and low-level inversion forecasting "apps" have been difficult to develop given the interference of objects that can obstruct wind flow such as farm buildings, tree lines, and adjacent crops (Hall et al. 2015). The data from this study can be utilized to validate inversion forecasting apps that seek to assist U.S. crop producers with numerous agriculture-related challenges including pesticide applications, frost warnings for fruit trees, and gas emissions from livestock (Ribeiro et al. 2006; Stieger et al. 2015; Battany 2012). 

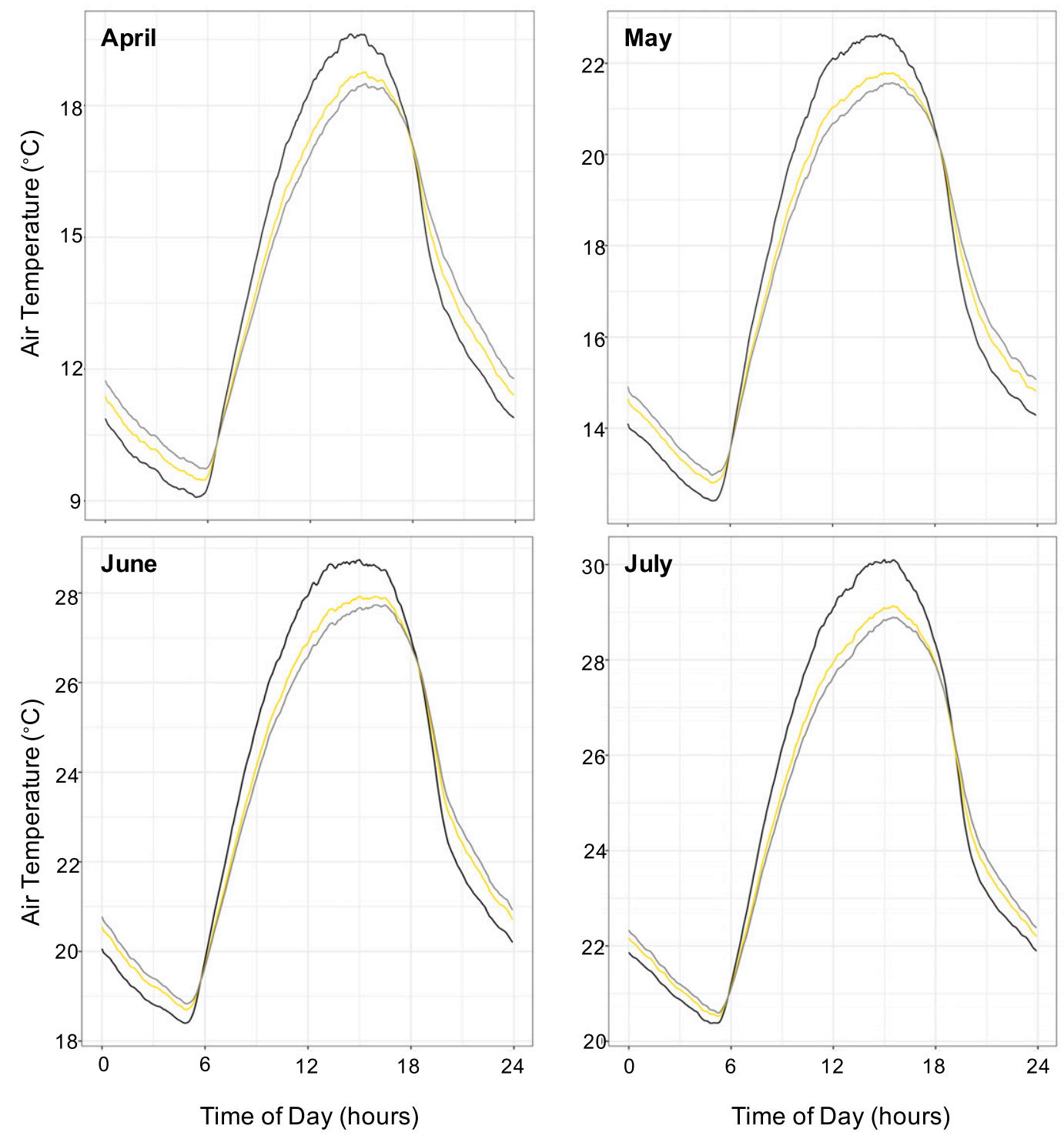

FIG. 4. As in Fig. 3, but in Columbia.

\section{Data and methods}

\section{a. Site descriptions and equipping weather stations}

Three currently existing research micrometeorological stations were utilized for this study. Of the 34 stations operated and maintained by the University of Missouri's Missouri Climate Center, three were selected given their locations in areas of high soybean production (Fig. 1) (USDA 2012). The Hundley Whaley Research Center (Fig. 2a), located in the northwestern portion of the state in Albany, Missouri, is within the northern plains region that covers approximately $32.3 \%$ of Missouri (Thom and Wilson 1983). The research center and weather station sit within a low-lying area at the bottom of a downward slope to the west of town, making the site subject to cold-air drainage. Prevailing winds at $305 \mathrm{~cm}$ AGL are from the south-southeast to south, and the nearest obstruction to wind from that direction was a building located $243 \mathrm{~m}$ due south (Massey and Guinan 2011; University of Missouri Commercial Agriculture 2019). This station was inactive because of a storm from 28 to 29 June 2017; therefore, no data are presented for those $24 \mathrm{~h}$. The site is at an elevation of approximately $80 \mathrm{~m}$. Bradford Research Center (Fig. 2b) is located centrally within the state near Columbia, Missouri, a region where the northern plains intersect the Ozark highlands (13.2\% of the state) (Thom and Wilson 1983) with an elevation of approximately $270 \mathrm{~m}$. Prevailing winds at $305 \mathrm{~cm}$ AGL were from the south, and the nearest obstruction to wind from that direction was a field plot that was left fallow or 



FIG. 5. As in Fig. 3, but in Hayward.

planted to corn, soybean, or wheat, depending on the year and was $194 \mathrm{~m}$ south-southeast (Massey and Guinan 2011; University of Missouri Commercial Agriculture 2019). The Lee Farm (Fig. 2c) is located near Hayward, Missouri, in the southeastern "bootheel" region of the state in the floodplains between the Mississippi and Saint Francis Rivers, and the land is distinctly flat with an elevation of $84 \mathrm{~m}$. Prevailing winds at $305 \mathrm{~cm}$ AGL were from the south, and the nearest obstruction to wind from that direction was a tree line $76 \mathrm{~m}$ due south (Massey and Guinan 2011; University of Missouri Commercial Agriculture 2019). Although the bootheel region represents approximately $5.2 \%$ of the state's geography, this area of Missouri is a highly productive agricultural area, in terms of percent of land in crop production, according to the 2012 National Agricultural Census Data (Thom and Wilson 1983; USDA 2012).

All three stations are situated in grass alleys on the respective farms. The grass directly underneath the stations is controlled by mechanical and/or chemical removal. The soil at both Albany and Columbia sites is silt loam. Soil at the Hayward site is a mix of silt loam (78\%), clay (16\%), and sandy loam (6\%) (USDA 2017). The Köppen climate classification zone for Albany and Columbia is Dfa (humid continental climate), and Hayward is classified as Cfa (humid subtropical climate) (Beck et al. 2018).

Each weather station was equipped with Vaisala/ Campbell Scientific temperature/relative humidity probes (model HMP60-L1-PT) to monitor air and dewpoint 
TABLE 1. The number of evenings per growing season in which inversions formed and the average daily solar radiation during the same time period. The archived historical average hourly solar radiation data were utilized.

\begin{tabular}{lccc}
\hline \hline Site & Year & $\begin{array}{c}\text { No. of evenings } \\
\text { with inversions }\end{array}$ & $\begin{array}{c}\text { Avg solar } \\
\text { radiation }\left(\mathrm{W} \mathrm{m}^{-2}\right)\end{array}$ \\
\hline Albany & 2015 & 44 & 204 \\
& 2016 & 65 & 226 \\
& 2017 & 71 & 235 \\
Columbia & 2015 & 53 & $217^{\mathrm{a}}$ \\
& 2016 & 69 & 231 \\
& 2017 & 76 & 236 \\
Hayward & 2015 & 60 & 211 \\
& 2016 & 74 & 225 \\
& 2017 & $64^{\mathrm{b}}$ & 227 \\
\hline
\end{tabular}

${ }^{\text {a }}$ Solar radiation data for April 2015 in Columbia were unavailable and were not included.

${ }^{\mathrm{b}}$ Inversion data for June 2017 were omitted because of interference with the 46-cm air temperature sensor.

temperatures and relative humidity at 46,168 , and $305 \mathrm{~cm}$ above Earth's surface. Naturally aspirated, 12plate Gill radiation shields (Campbell Scientific, Inc., model 41002) were installed to minimize the artificial heating effect during bright-sunlight, low-wind conditions. Cup anemometers were utilized to record wind speeds and directions at $305 \mathrm{~cm}$ above ground level. Stations were physically inspected each month and following storm events to ensure no obstructions by either interference or shading of the temperature probes and to confirm all instruments were in working order. Weather data were monitored routinely by studying air temperature, dewpoint, and wind charts on a weekly to semiweekly basis to identify anomalies that would suggest station error and need for maintenance. Obstructed data were removed from the analysis.

\section{b. Basic characterization of temperature inversions}

Real-time weather data were utilized for this study. The sampling rate for the probes was every three seconds. Three-second samples were combined into 5-min averages, and the 5-min averages were utilized for analysis. For this climatology, inversion events were classified as occurring if 1) the air temperatures at $305 \mathrm{~cm}>$ air temperatures at $46 \mathrm{~cm}$ and air temperatures at $168 \mathrm{~cm}>$ air temperatures at $46 \mathrm{~cm}, 2$ ) temperatures remained inverted for $\geq 1 \mathrm{~h}$ in duration, and 3) the air temperature difference between 46 and $305 \mathrm{~cm}$ exceeded $1.3^{\circ} \mathrm{C}$ at some point during the event. The $1.3^{\circ} \mathrm{C}$ temperature difference $\Delta T$ spans the accuracy limitations of the temperature probes, which have a range of $\pm 0.6^{\circ} \mathrm{C}$. An event was counted as an inversion if $\Delta T$ exceeded $1.3^{\circ} \mathrm{C}$ temperature difference criteria at some point during the event, which is a similar approach to the one employed by Hosler (1961) in tallying inversion events. Lifted inversions $(305>46$ and $168<46 \mathrm{~cm}$ ) were not considered in this analysis for practical reasons. Most ground pesticide applications occur between 46 and $168 \mathrm{~cm}$. However, not all will occur at those heights, and the range of $46-305 \mathrm{~cm}$ should encompass all ground pesticide applications. The 5-min weather data corresponding to inversions were output into a Microsoft, Inc., Excel worksheet that could be utilized for further analysis in the software programs SAS, version 9.4, and R, version 3.5, "Joy in Playing," which was used to generate graphs and boxplots.

\section{c. Data analysis}

Data were analyzed utilizing difference procedures in SAS 9.4, including PROC MEANS and PROC CORR. The MEANS procedure allowed calculation of descriptive statistics and estimation of quantiles to describe inversions. Mean, mode, median, and quartiles were calculated for each month by site. The three years were combined for each month by site. SAS 9.4 analysis of time requires time to be in seconds. Before running the MEANS procedure data were converted using a modular arithmetic approach in which noon represented time 0 and midnight represented 43200 s. After analysis, the data were then converted back to hour: minute format. The CORR procedure was used to produce Pearson and Spearman correlation coefficients and determine the strength of linear and monotonic relationships between the measured weather variables described in section 2 a during inversion and noninversion conditions.

\section{Results}

\section{a. Basic characterization of low-level inversions}

April, May, June, and July are the predominant months in Missouri in which pesticide applications occur in soybean production. The mean air temperature for each height AGL was graphed for April, May, June, and July using the 5-min temperature averages over the course of 2015-17. The plotted averages revealed that generally, air temperatures at $46 \mathrm{~cm}$ were cooler than the $305-\mathrm{cm}$ air temperature during evenings at each location (Figs. 3-5). The standard deviation for each air temperature is graphed for the same time periods (appendix A) and suggests that the probes at each height behaved similarly over the course of the study. Wind speeds also showed an expected trend of peaking at midday and decreasing near dusk, which would coincide with nocturnal inversions. The 2015-17 five-minute wind 
Albany
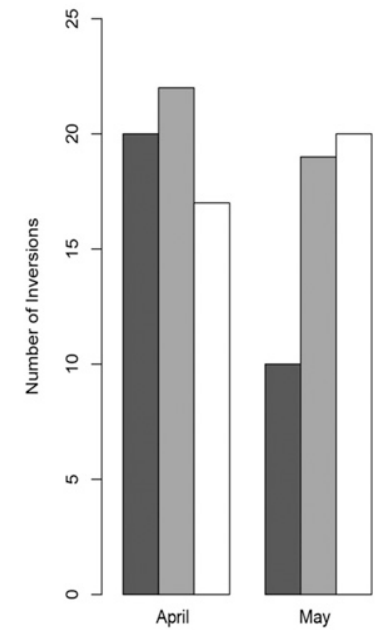

May

Hayward

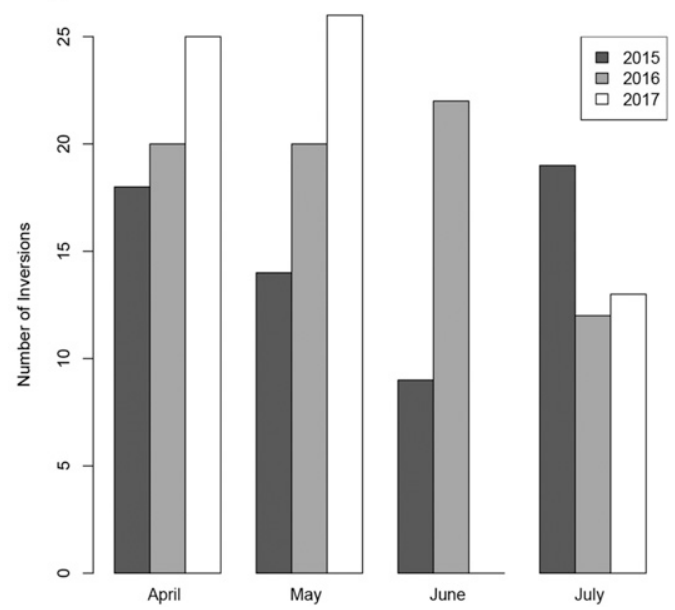

Columbia

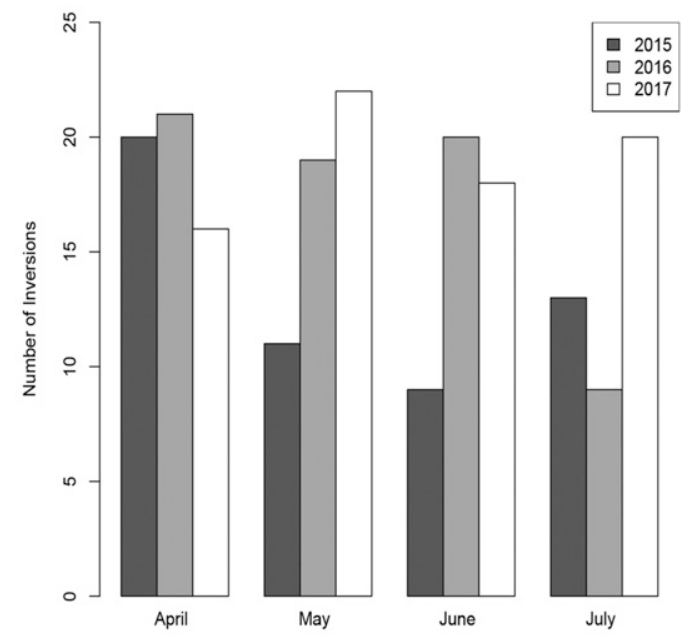

FIG. 6. Number of days per month in which inversions formed. Inversion events from June 2017 at Hayward were not included because of interference by nearby vegetation that resulted in artificial shading of the sensor. speed averages were similar to the 10 -yr, hourly, historical averages for each site (appendix A).

The air temperature trends at the Albany location differed from those at Columbia and Hayward for the months of June and July in that temperature at the $168-\mathrm{cm}$ height was similar to the $46-\mathrm{cm}$ air temperature during the overnight hours (Fig. 3). At Columbia and Hayward, the 46- $\mathrm{cm}$ air temperature trended lower than the $168-\mathrm{cm}$ air temperature during the evenings across all months. One possible explanation for the differences observed at Albany is topography. The trend suggests that the cool stable airmass depth that forms as a result of inverted temperatures is greater at the Albany site when compared with the other two locations. The Albany station, unlike the other two, is in a low-lying area adjacent to an upward slope to the east and is subject to cool air drainage, which could account for a deeper pool of cool, stable air. During daytime hours, the air temperature at $168 \mathrm{~cm}$ was similar to $305 \mathrm{~cm}$ at both Albany and Hayward locations. The difference observed at Albany and Hayward relative to Columbia, in which day time air temperatures were coolest at $305 \mathrm{~cm}$ and warmest at $46 \mathrm{~cm}$, could be due to topography or possibly that Albany and Hayward have more objects nearby that could obstruct or alter wind patterns and influence air temperatures (Fig. 2).

\section{1) FREQUENCY OF INVERSION OCCURRENCES}

Inversions were identified for each location, month, and year studied. However, data for June 2017 at Hayward were omitted from the study because of artificial shading of the $46-\mathrm{cm}$ sensor by a nearby pollinator planting. All inversions detected during this study were nocturnal in nature. Collectively, fewer inversions occurred over the 2015 growing season relative to 2016 and 2017 at all sites (Table 1). One possible contributor to the differences observed 

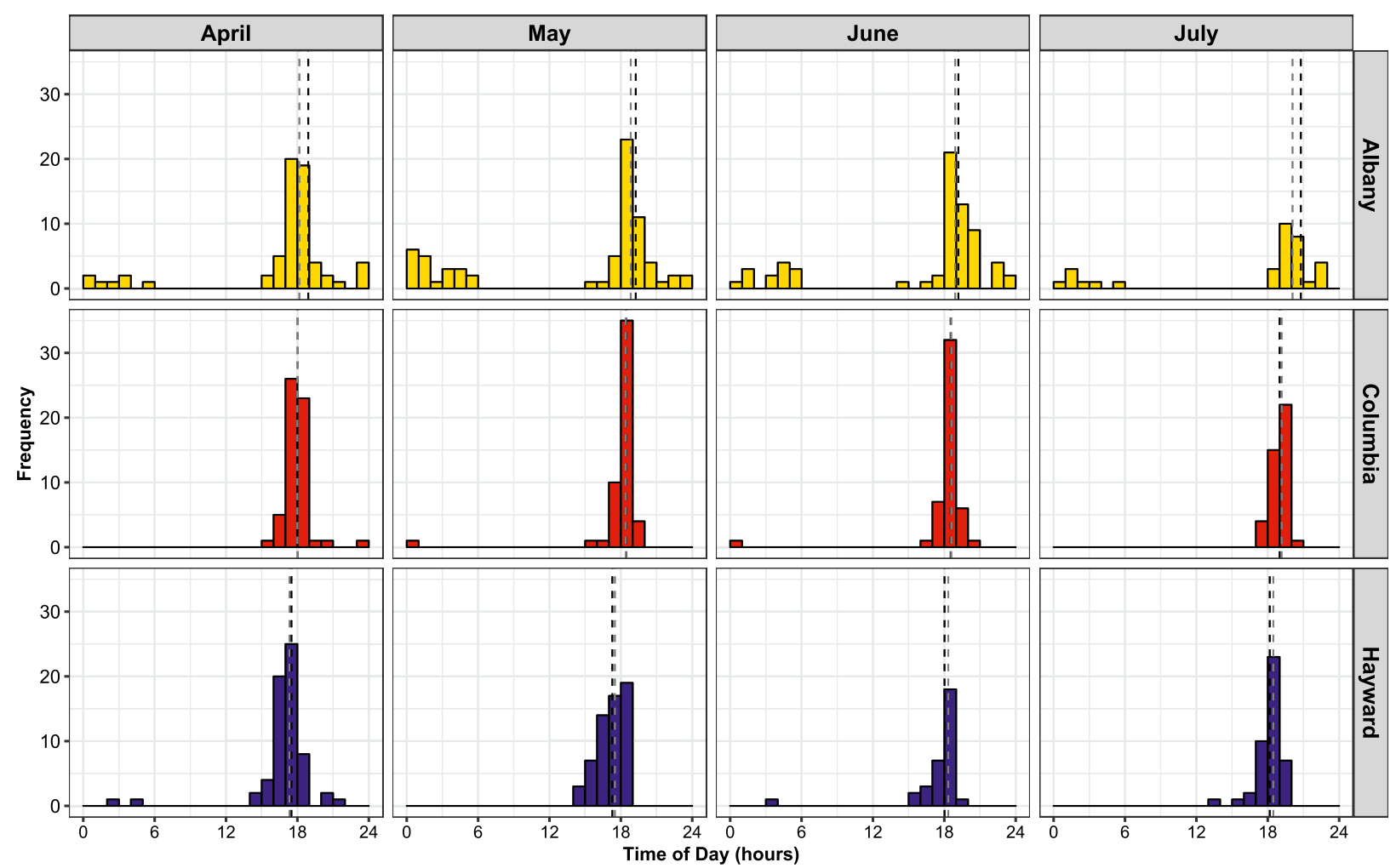

FIG. 7. The frequency of inversions that formed during each 15-min time interval throughout the day. Each month and site are graphed across all years studied (2015-17). Mean and median start times for each month and site are represented by the black and gray dashed lines, respectively.

between 2015 and the other two years 2016 and 2017 is that all sites received, on average, less solar radiation per day in 2015 than in the other two years (Table 1). Record rainfalls were observed in 2015 along with higher-than-normal cloud coverage, which likely contributed to the lower solar radiation (Guinan 2015a,b). Less solar radiation indicates an increased presence of low-level or midlevel layered clouds in 2015; such an increased cloud presence could reduce average solar radiation and interfere with inversion formation by trapping radiation in the atmosphere (Matuszko 2012; Monahan et al. 2015). For the Albany location, July of 2015 and 2016 had the least number of evenings in which inversions formed with six nights out of each month (Fig. 6a) whereas inversions formed on 15 evenings in July of 2017. April of 2016 had the most evenings in which inversions were observed with 22 (Fig. 6a). At the Columbia site, June of 2015 and July of 2016 had the least number of evenings in which inversions formed with 9 each (Fig. 6b). The maximum number of evenings per month in which inversions were observed was 22 evenings in May 2017. At the Hayward location, June of 2015 had the least number of evenings in which inversions formed with 9 (Fig. 6c). May of 2017 had 26 evenings in which inversions formed; this was the most observed of any months across sites and years.

\section{2) FormATION TIMES FOR INVERSION EVENTS}

The times at which inversions began forming are graphed in the histogram in Fig. 7, which shows the distribution of start times by location and month. Start time was considered as the initial time point in which the air at $46 \mathrm{~cm}$ had cooled and reached a lower temperature than both the 168 - and $305-\mathrm{cm}$ air temperatures. Albany had the most variation with regard to start time as shown in Fig. 7 (see also the basic summary statistics in appendix B). Inversions typically began forming between 1800 and 1900 local time (LT) at Albany; however, there were multiple evenings in which inversions began forming between midnight and $0600 \mathrm{LT}$, which influenced the mean start time and deviation from the mean. The Columbia and Hayward locations were more consistent with regard to start times. The mean, median, and mode start times at Columbia ranged from 1800 to 1915 LT across all months. Hayward, which is south and notably east of the other two sites, had slightly earlier start times 


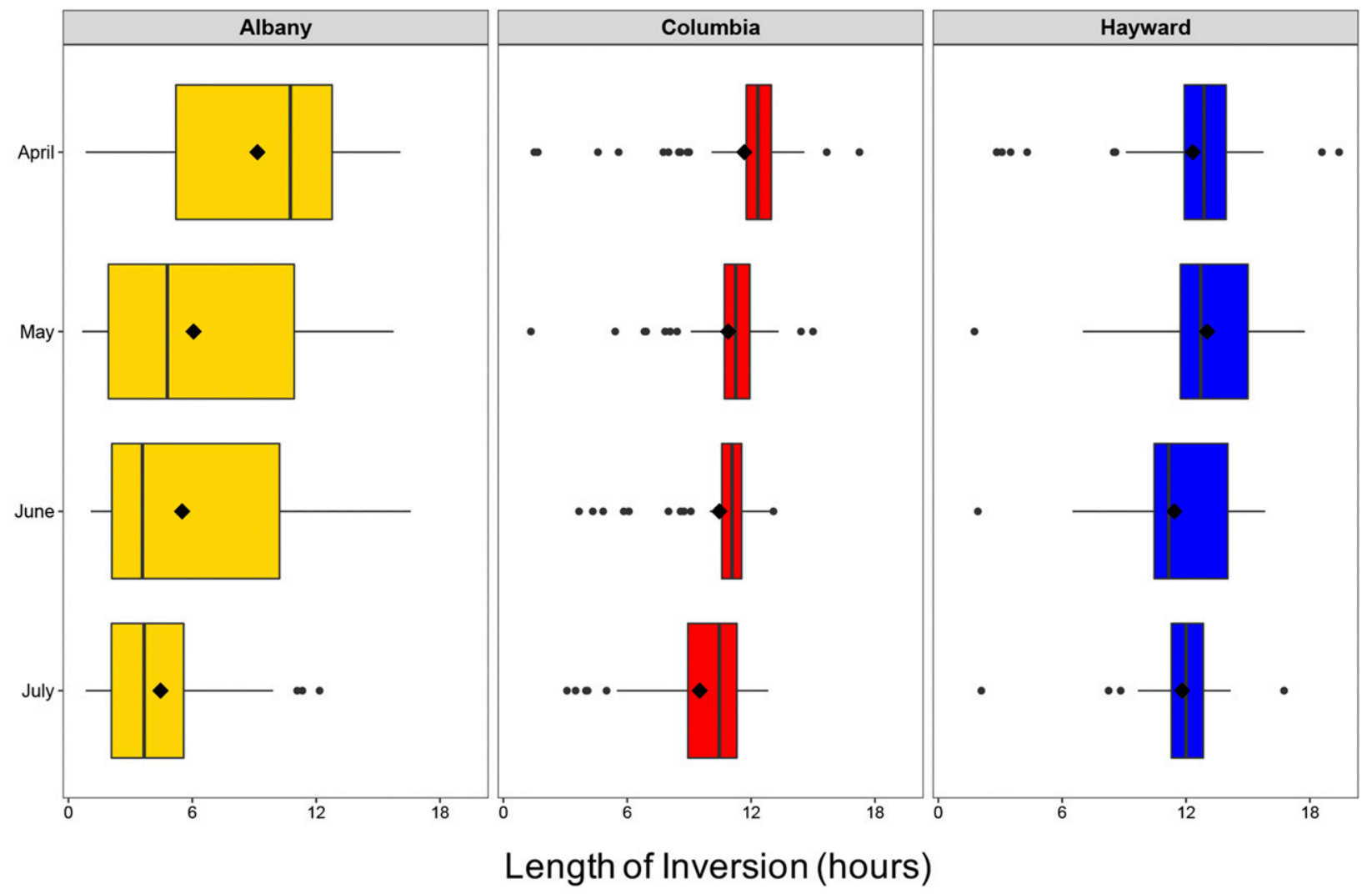

FIG. 8. Boxplot showing typical duration of inversions at each location over the course of the growing season from 2015 to 2017 . The vertical black line in each box represents median duration time. Mean inversion duration is represented by a black diamond; boxes represent the interquartile range (IQR), with the left and right edges representing the lower (25\%) and upper (75\%) quartiles, respectively. Horizontal lines represent the reasonable extreme distances of the data from the IQR $(1.5 \times$ IQR). Filled circles represent outliers.

across all months studied; the mean and median start time ranged from 1730 to $1830 \mathrm{LT}$, depending on month.

\section{3) DURATIONS OF INVERSIONS AND INVERSION END}

Duration of inversion events varied by site as shown in the boxplot in Fig. 8. The longest inversions recorded at each site occurred in April. An inversion of $16 \mathrm{~h} 5 \mathrm{~min}$ was recorded in Albany, $17 \mathrm{~h} 15 \mathrm{~min}$ in Columbia, and $19 \mathrm{~h} 25 \mathrm{~min}$ in Hayward (Fig. 8). However, differences in inversion duration were observed among the sites and months. At the Albany location, the average inversion duration was typically longest in April, with a mean duration of $9 \mathrm{~h} 38 \mathrm{~min}$ and decreased across months: May inversions averaged $6 \mathrm{~h} 4 \mathrm{~min}$ in length; June averaged $5 \mathrm{~h} 30 \mathrm{~min}$, and July averaged $4 \mathrm{~h} 28 \mathrm{~min}$. In Columbia, a similar trend occurred over the months; however, differences were less pronounced. The mean inversion duration in April was $11 \mathrm{~h} 40 \mathrm{~min}$, in May was $10 \mathrm{~h} 53 \mathrm{~min}$, June was $10 \mathrm{~h} 28 \mathrm{~min}$, and July was $9 \mathrm{~h} 30 \mathrm{~min}$. Duration of inversions at Hayward did not decline in the same fashion as Albany and Columbia, and mean duration ranged from $11 \mathrm{~h} 26 \mathrm{~min}$ to $13 \mathrm{~h} 1 \mathrm{~min}$ depending on month. The Hayward site is the most sheltered station with a tree corridor to the south and a building to the west. Prevailing winds are from the south during the growing season, and the shelters reduce that wind, which would impact the timings of inversion formation and dissipation (appendix A). Reduced wind speeds may be indicative of less vertical air mixing, which could coincide with a longer duration of inverted temperatures. One possible explanation for the variation observed at Albany is the trend observed for the air temperatures at 46- and 168-cm heights as shown in Fig. 3. These air temperatures tend to be similar, with the $168-\mathrm{cm}$ height being cooler than the $46-\mathrm{cm}$ height at some point during the evening and disrupting the inversion.

Inversion end time was defined as the time at which air temperature at $46 \mathrm{~cm}$ became warmer than the air temperature at $305 \mathrm{~cm}$. This typically occurred near sunrise (Table 2). The Albany location again had the most variation as conveyed by the differences in mean in 
TABLE 2. Basic statistics describing 3-yr trends in inversion end time (LT) at each site over each month of the soybean growing season (2015-17).

\begin{tabular}{|c|c|c|c|c|c|c|c|}
\hline & Month & $n$ & Mean \pm h:min ${ }^{a}$ & Median & Mode & Earliest & Latest \\
\hline \multirow{4}{*}{ Albany } & Apr & 64 & $0722 \pm 5: 26$ & 0640 & 0640 & 0035 & 2355 \\
\hline & May & 70 & $0801 \pm 6: 15$ & 0630 & 0635 & 0005 & 2355 \\
\hline & Jun & 66 & $1034 \pm 8: 21$ & 0625 & 0620 & 0015 & 2345 \\
\hline & Jul & 33 & $0757 \pm 9: 04$ & 0540 & 0105 & 0005 & 2350 \\
\hline \multirow[t]{4}{*}{ Columbia } & Apr & 58 & $0618 \pm 2: 46$ & 0625 & 0635 & 0055 & 2305 \\
\hline & May & 52 & $0612 \pm 3: 20$ & 0555 & 0545 & 0105 & 2305 \\
\hline & Jun & 48 & $0608 \pm 3: 43$ & 0545 & 050 & 0030 & 2305 \\
\hline & Jul & 42 & $0648 \pm 5: 30$ & 0545 & $05: 45$ & 0000 & 2315 \\
\hline \multirow[t]{4}{*}{ Hayward } & Apr & 64 & $0648 \pm 2: 47$ & 0630 & 0615 & 0035 & 2025 \\
\hline & May & 60 & $0649 \pm 2: 07$ & 0630 & 0555 & 0045 & 1835 \\
\hline & Jun $^{\mathrm{b}}$ & 32 & $0553 \pm 1: 20$ & 0540 & 0220 & 0220 & 0800 \\
\hline & Jul & 43 & $0634 \pm 1: 55$ & 0630 & 0640 & 0325 & 1745 \\
\hline
\end{tabular}

${ }^{\text {a }}$ Statistics were run in SAS 9.4, which converts hour and minutes to seconds and runs the analysis, and then the data are converted back to hours and minutes.

${ }^{\mathrm{b}}$ June 2017 was excluded from the analysis because of interference of the $46-\mathrm{cm}$ air temperature probe by shading from a pollinator plot.

comparison with the median and mode end times. With the exception of mode for July, which was 0105 LT, all median and mode dissipation times were within 0540-0640 LT Columbia had the least variation in end time; mean, median, and mode values for dissipation were between 0545 and 0648 LT regardless of month.
Inversion end times at Hayward were also consistent with the exception of mode in June, which was 0220 LT. Mean, median, and mode dissipation times fell within 0540-0649 LT. A closer look at the June data indicated two inversion events on 26 and 27 June 2016 that dissipated at 0220 LT. Given the smaller sample size for June inversions at

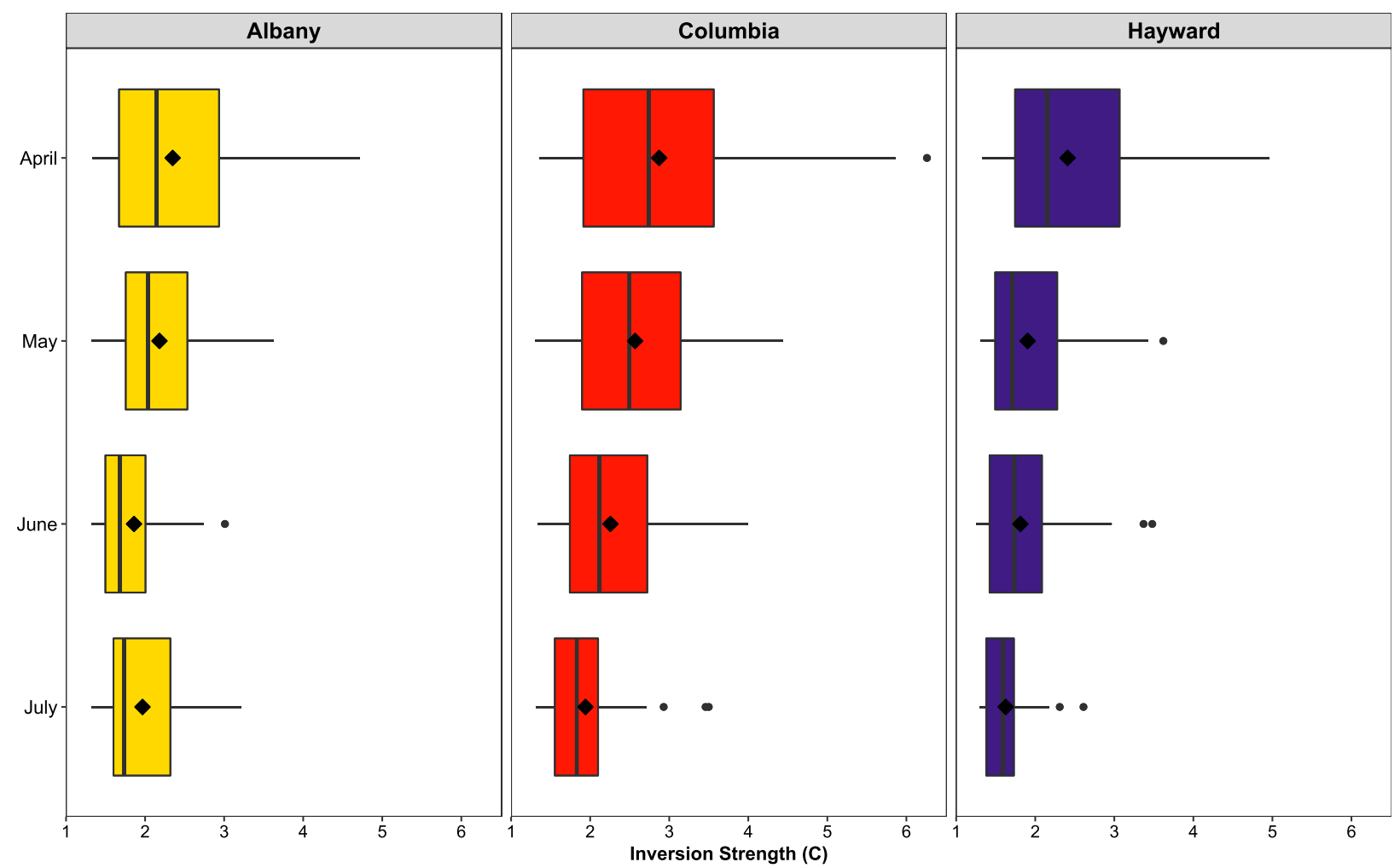

FIG. 9. As in Fig. 8, but showing the maximum $\Delta T$ between the 305- and 46-cm heights during each inversion event; here the vertical black line in each box represents median strength. 


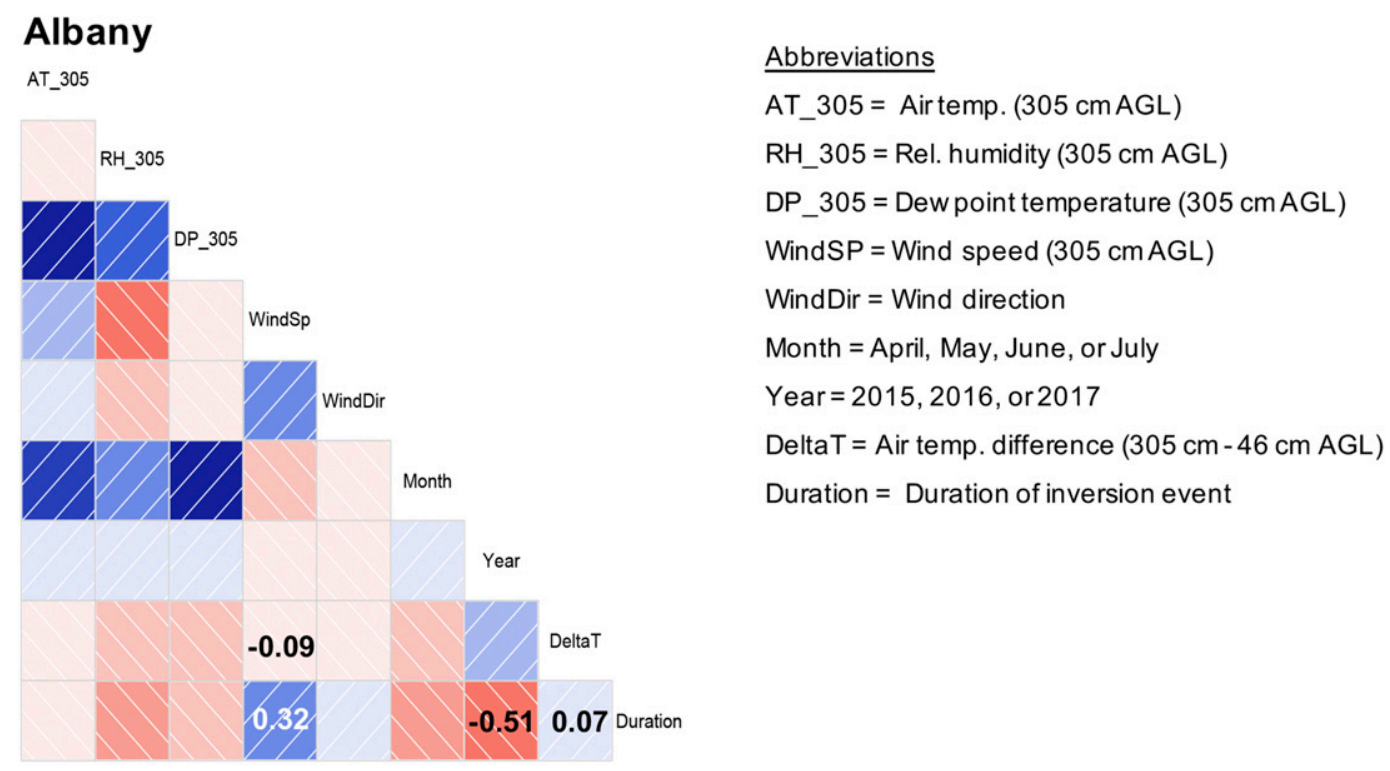

\section{Columbia}

\section{Hayward}
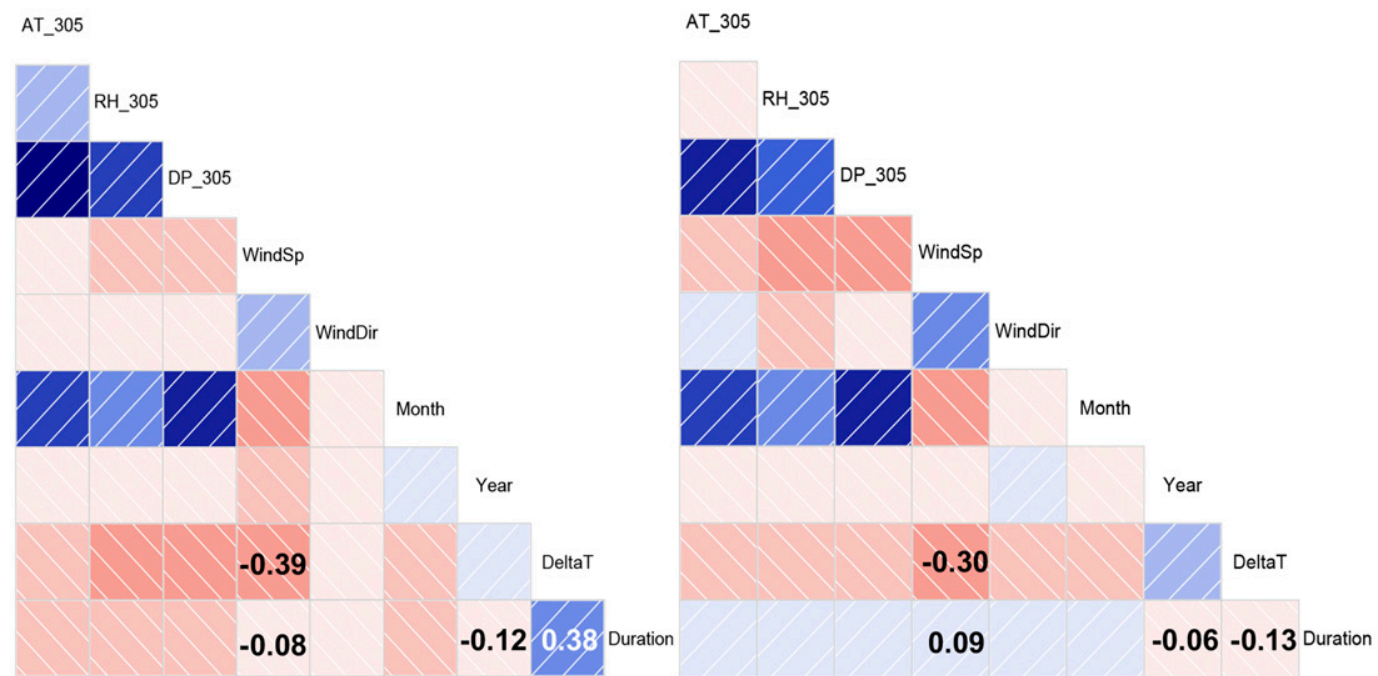

FIG. 10. Correlograms highlighting correlation relationships among variables during inversion conditions. The studied variables are described at the top right. The darker the color of the box is, the stronger is the correlation. Blue signifies a positive correlation relationship, and red indicates a negative relationship. Correlation coefficient values that are included in the boxes are discussed further in the text. All coefficient values are listed in appendix $\mathrm{C}(p<0.001)$.

Hayward, because of the aforementioned pollinator plot interference, those two events were enough to affect mode.

\section{4) INVERSION STRENGTH}

Changes in the air temperature profile over increasing heights AGL is one indicator of atmospheric stability (Yates et al. 1974; Poulos et al. 2002). As air temperatures higher AGL become warmer, the more stable the atmosphere and less likely particles are to disperse vertically and become more susceptible to horizontal wind movement (Fritz et al. 2008). Maximum air temperature differences between the 305- and 46-cm heights $(\Delta T)$ are shown in the boxplot in Fig. 9. The highest $\Delta T$ at each location were observed in April. Inversions occurring in April were typically longer in duration than inversions forming in other months, and the longer duration likely allowed more time for the stable air mass to form and contributes to larger $\Delta T$. Columbia had the greatest differences observed for each month, reaching a $\Delta T$ of greater than $6^{\circ} \mathrm{C}$ during one event in April. The 


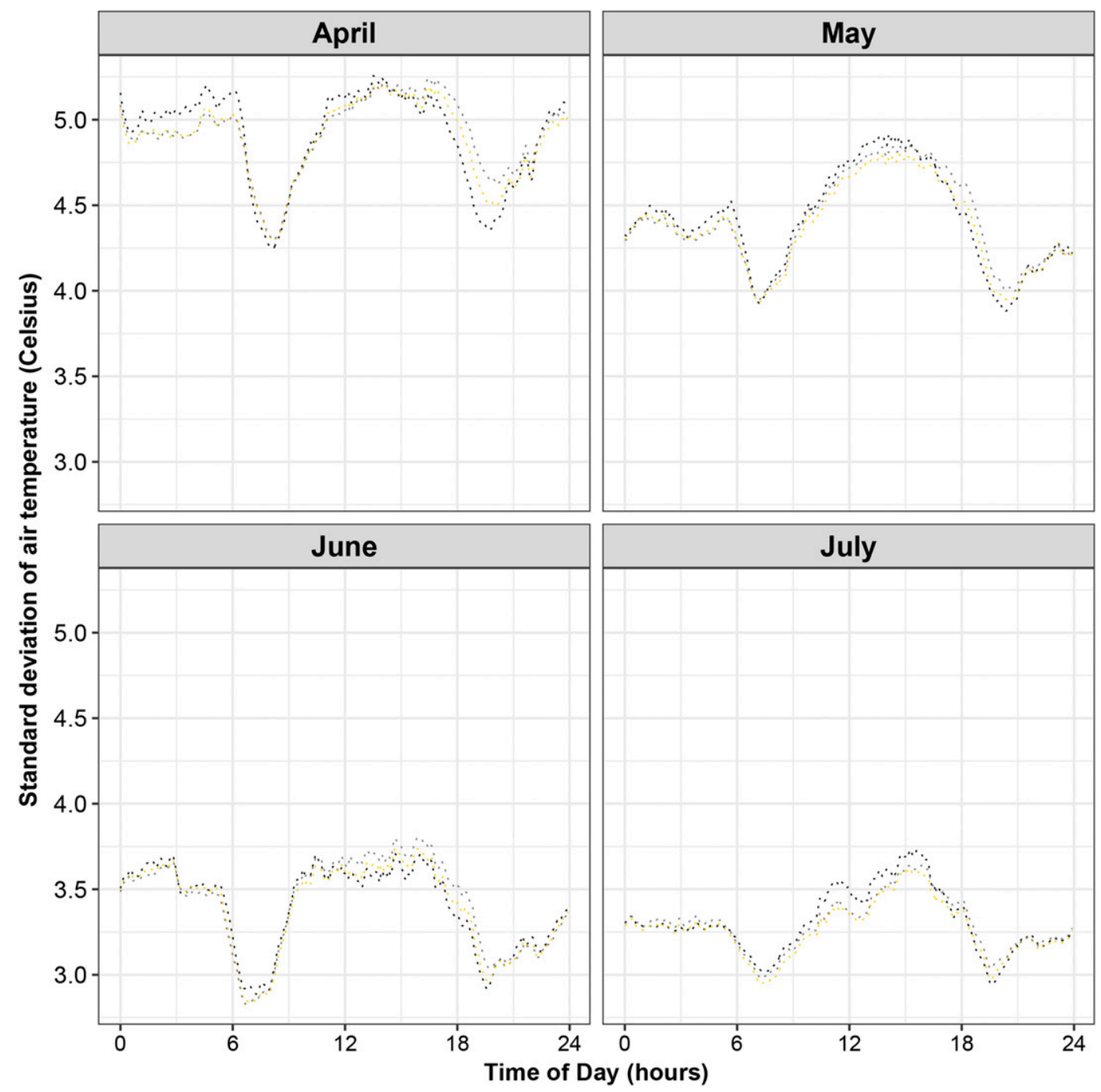

FIG. A1. Standard deviation (SD) of the 5-min air temperatures at each height in Albany from 2015 to 2017 during the growing season. Black, gold, and gray dotted lines indicate the standard deviation at 46, 168, and $305 \mathrm{~cm}$, respectively.

$\Delta T$ at Albany and Columbia decreased over the course of the growing season, again possibly because of shortening of the duration of inversion events. At Hayward, where inversion duration was similar across months, there were fewer differences observed in the $\Delta T$ across months, although $\Delta T$ for June and July were smaller than those observed in April.

\section{b. Exploring relationships among weather variables}

In addition to air temperatures, measurements of wind speed, wind direction, relative humidity, and dewpoint temperatures were also recorded in 5-min intervals for each location. Relationships among these variables during inversion conditions compared to noninversion conditions were evaluated by calculating Pearson's correlation coefficients. To simplify presentation of the data only air temperature, dewpoint temperature and relative humidity at $305 \mathrm{~cm}$ are presented because relationships for the $305-\mathrm{cm}$ data when compared with $46-$ and $168-\mathrm{cm}$ data were very similar. The correlograms in Fig. 10 show correlation relationships between variables during inversion conditions at each site. A subset of the Pearson's correlation coefficient values that will be discussed are included in the diagram. For a full list of Pearson's correlation coefficient values, see appendix C. A positive correlation was observed at Columbia between $\Delta T$ and duration of inversion, which was consistent with the observed decrease in duration and strength across months at Columbia (Figs. 8 and 9). Correlation coefficients 


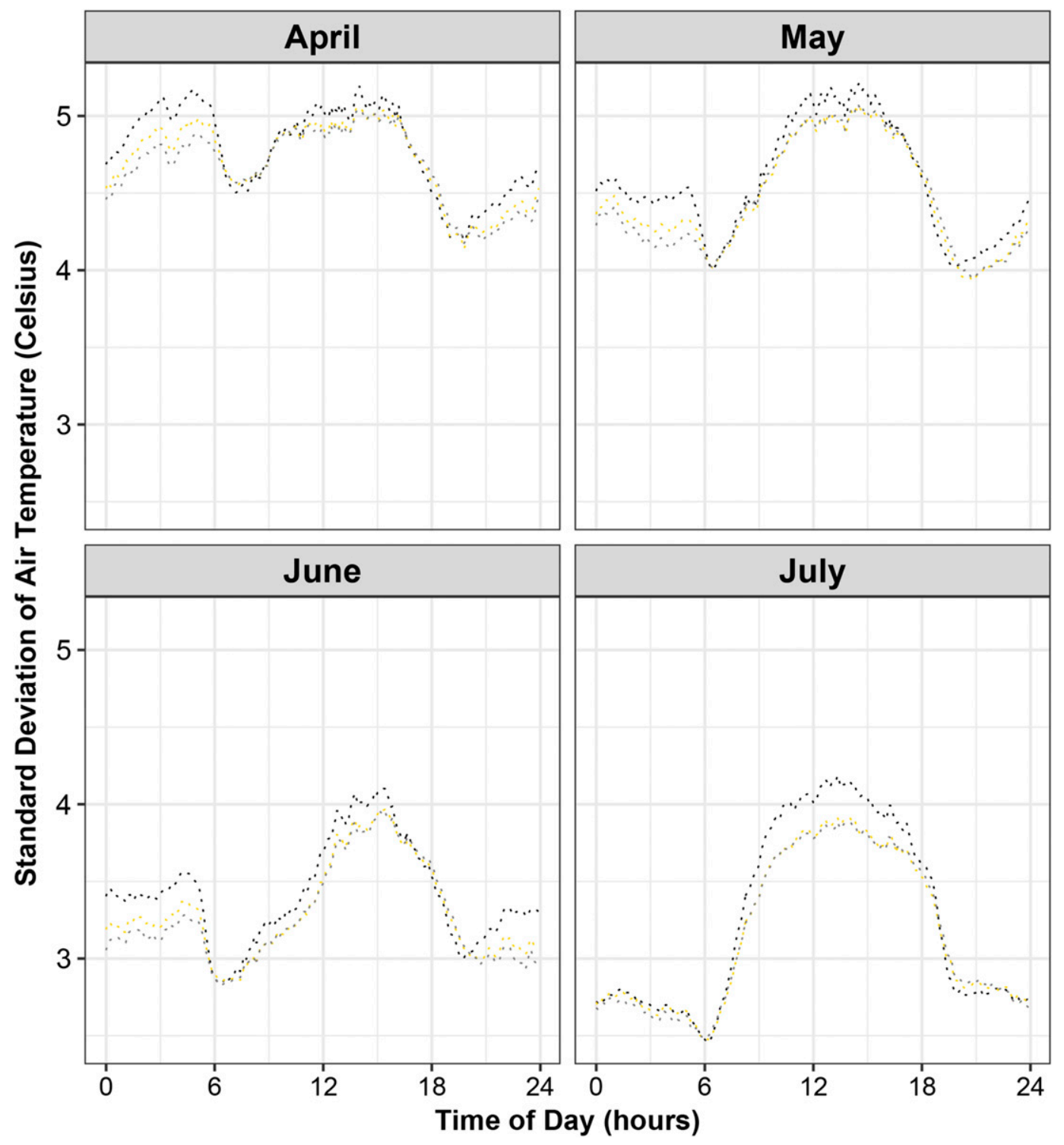

FIG. A2. As in Fig. A1, but in Columbia.

between wind speed and $\Delta T$ were negative and similar at Columbia and Hayward sites, suggesting that, as $\Delta T$ increased, wind speed decreased. Interestingly, a similar relationship was not observed at Albany as the correlation was almost zero between the two variables. There was a positive relationship between wind speed and inversion duration at Albany that was not observed at the other two sites. The differences in wind speed relationships that were observed at Albany compared to Columbia and Hayward may provide more evidence for a role of drainage winds in cooling air temperatures at the lower heights at the Albany location. The differences between Albany and the other two sites, combined with the strong correlation coefficient for year and duration of inversion at Albany, also suggest that more site years may be needed to understand inversion climatology at Albany compared to the other two sites.

All sites were then combined, and data were analyzed and compared between inversion and noninversion conditions. The strongest correlation observed with all sites combined that was unique for inversion conditions was a coefficient of 0.34 between wind speed and wind direction (appendix C). The correlation was 0.11 for noninversion conditions. The strongest correlation observed that was unique to noninversion conditions was $\Delta T$ and relative humidity, which had a coefficient of 0.45 . It was nearly opposite of inversion conditions in which the correlation coefficient was -0.29 . The negative relationship between 


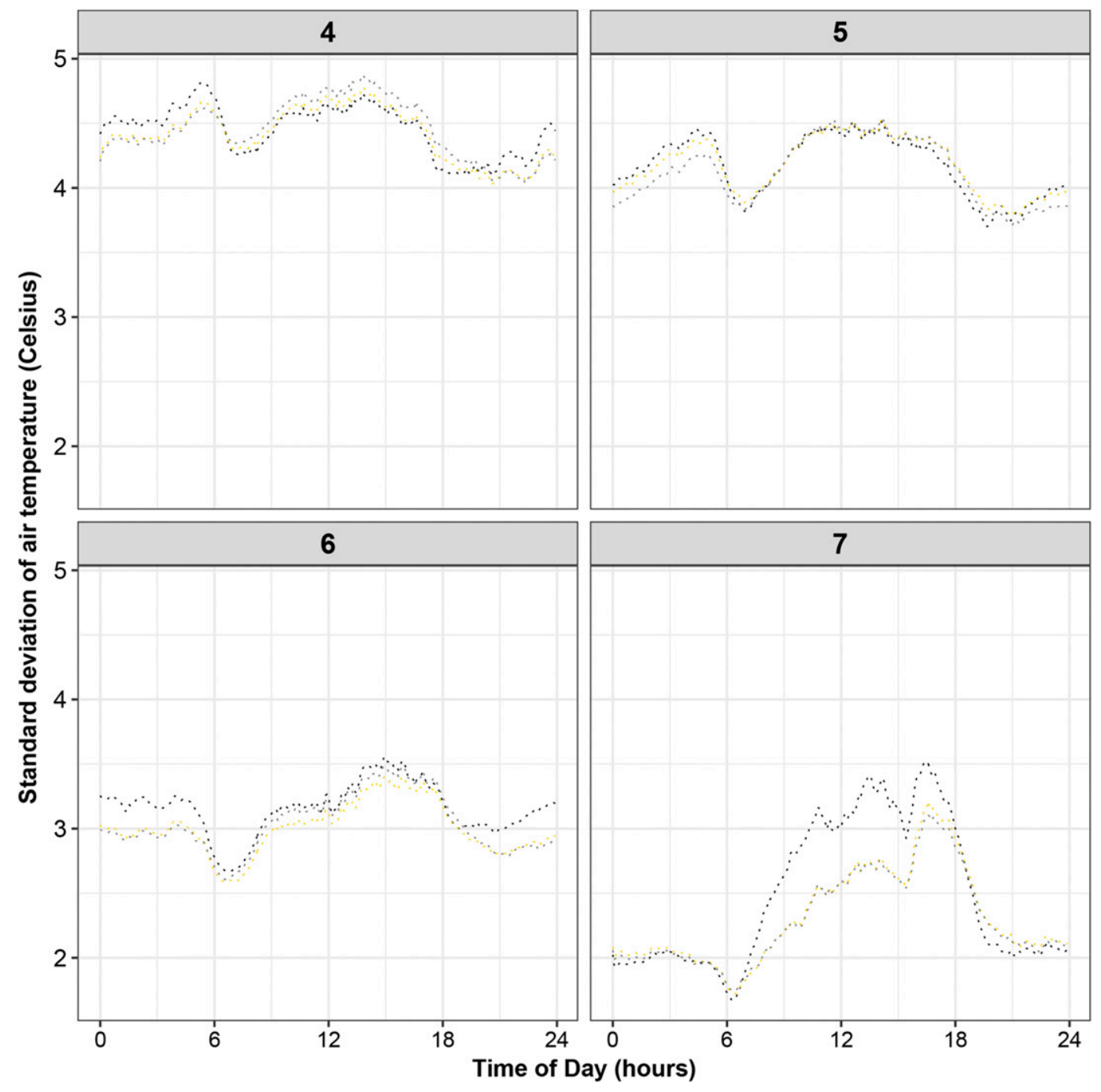

FIG. A3. As in Fig. A1, but in Hayward. Here, 4-7 indicate April-July.

relative humidity and $\Delta T$ during inversion conditions was interesting in that pesticide applicators are commonly told to look for the presence of dew or fog as indicators of surface temperature inversions. However, these results would suggest dew and fog are not reliable indicators.

\section{Summary and conclusions}

There is an increased interest in understanding surface temperature inversions at heights relevant to ground pesticide applications because of the recent commercial introduction of soybean and cotton that are resistant to the synthetic auxin herbicide dicamba (USDA 2015a,b) and the subsequent increase in the number of dicamba-injury investigations. The work presented here provides initial inversion climatology for low-level temperature inversions $(46-305 \mathrm{~cm})$ over the course of three soybean growing seasons at three Missouri locations. All inversions identified were nocturnal in nature. There were some similarities among sites such as the times at which inversions began formingbetween 1700 and 2000 LT. This is an important finding in that it is common, during the soybean and cotton growing seasons to observe ground pesticide applicators making applications in those hours. Wind becomes less problematic and the possibility of physical drift is reduced. Historically, there has not been such a need for ground pesticide applicators to consider nocturnal temperature inversions, and many are unfamiliar with inversion characteristics (Bish and Bradley 2017).

Across all sites studied, the Albany location had the most variation in inversion formation time and duration. This weather station, which is set up in an area subject to cool air drainage, also had a positive correlation 


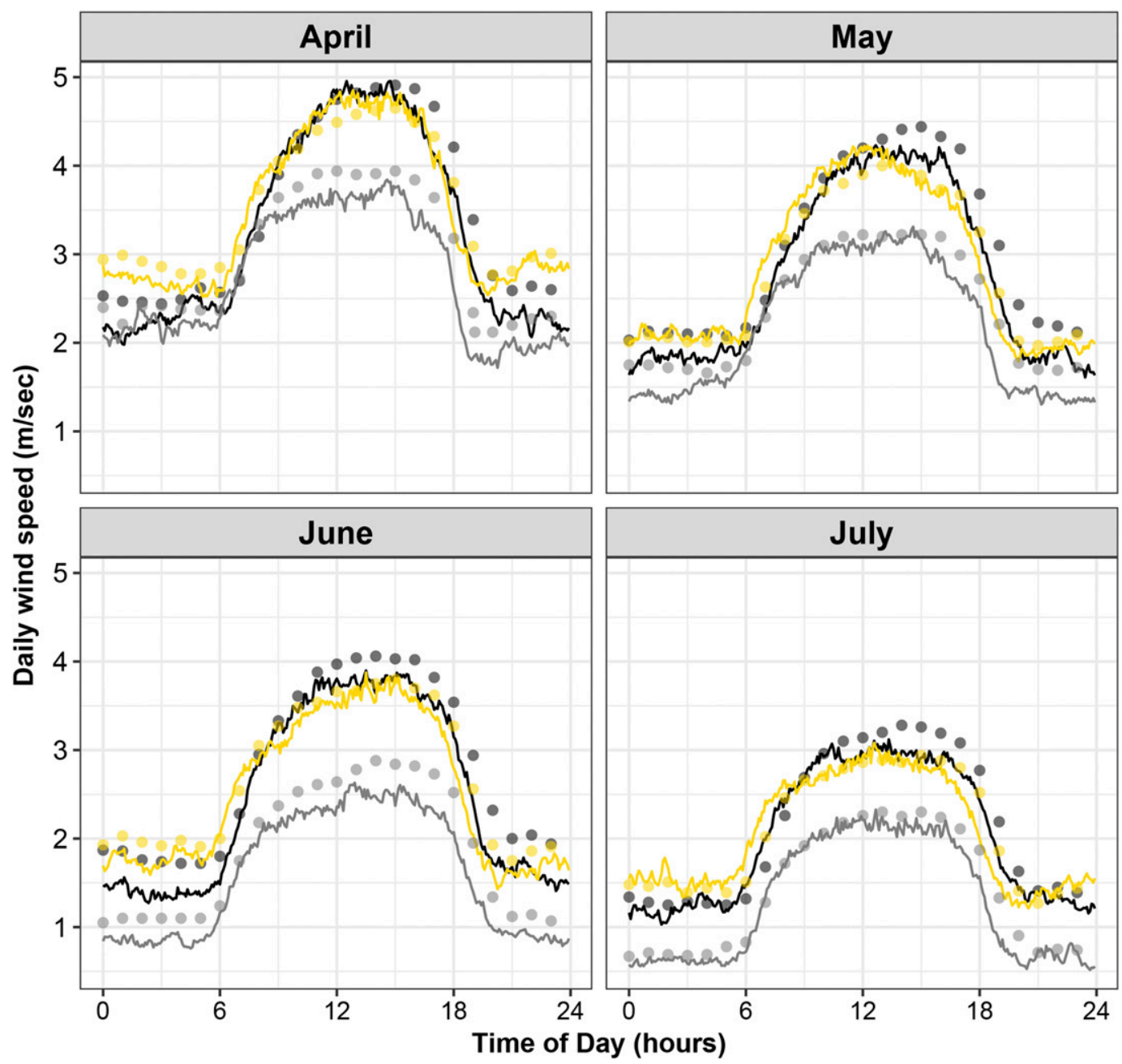

FIG. A4. Five-minute wind speed averages over the course of each studied month. The black solid line represents Albany, gold is Columbia, and gray is Hayward. Dotted lines are the 10-yr trends for hourly average wind speed at each respective site.

between wind speed and $\Delta T$. The other two sites were more consistent with regard to formation time and duration and had negative relationships between wind speed and $\Delta T$. Inversions at Columbia and Hayward began forming near sunset and dissipated near sunrise the next day, similar to previous reports that stable air masses begin forming near sunset and remain until sunrise (van Hooijdonk et al. 2017).

The 3-yr climatology profiles presented here and the differences observed between sites highlight the need to learn more about topography and its effects on low-level inversions relevant to ground pesticide applications. They also provide further support that more data are needed to address challenges associated with developing accurate inversion prediction models. Accurate predictive models are a challenge that has been reported by many groups previously because of the behavior of the lower atmosphere and variation in Earth's surface (van Hooijdonk et al. 2017; Monahan et al. 2015).

Another question that remains unknown is the extent to which these very low-level surface temperature inversions impede the dispersion of dicamba and other pesticides in the atmosphere. Recent work was conducted by Yassin et al. (2018) who collected air samples of pollutants for each hour of one year. From those data, they looked at the diurnal concentrations of specific compounds over a 24-h day. Nitric oxides, carbon monoxide, and nonmethane hydrocarbons were all found to have peak concentrations corresponding to times of day when the least amount of air mixing was occurring and near hour 20 of the day. This would correspond to the time frame in which nocturnal inversions are likely to have formed (Yassin et al. 2018). However, the 
TABLE B1. Three-year trend for (start) time at which inversions began forming (2015-17).

\begin{tabular}{|c|c|c|c|c|c|c|c|}
\hline & Month & $n^{\mathrm{a}}$ & Mean \pm h:min & Median & Mode & Earliest & Lates \\
\hline \multirow[t]{4}{*}{ Albany } & Apr & 64 & $1855 \pm 2: 33$ & 1810 & 1820 & 0040 & 2335 \\
\hline & May & 70 & $1915 \pm 2: 05$ & 1850 & 1815 & 0000 & 2335 \\
\hline & Jun & 66 & $1911 \pm 1: 32$ & 1855 & 1810 & 0005 & 2310 \\
\hline & Jul & 33 & $2047 \pm 2: 21$ & 2005 & 1930 & 0000 & 2240 \\
\hline \multirow[t]{4}{*}{ Columbia } & Apr & 58 & $1801 \pm 1: 03$ & 1800 & 1800 & 1550 & 2325 \\
\hline & May & 52 & $1827 \pm 1: 03$ & 1825 & 1845 & 0015 & 1925 \\
\hline & Jun & 48 & $1832 \pm 0: 38$ & 1835 & 1855 & 0100 & 2100 \\
\hline & Jul & 42 & $1900 \pm 0: 37$ & 1910 & 1915 & 1745 & 2040 \\
\hline \multirow[t]{4}{*}{ Hayward } & Apr & 64 & $1730 \pm 1: 43$ & 1720 & 1745 & 0245 & 2130 \\
\hline & May & 60 & $1717 \pm 1: 10$ & 1730 & 1830 & 1420 & 1855 \\
\hline & $\mathrm{Jun}^{\mathrm{b}}$ & 32 & $1801 \pm 0: 53$ & 1820 & 1830 & 0330 & 1905 \\
\hline & Jul & 33 & $1810 \pm 1: 03$ & 1828 & 1800 & 1350 & 2040 \\
\hline
\end{tabular}

a $n=$ number of inversion formations observed.

${ }^{\mathrm{b}}$ June 2017 was excluded from this analysis because of interference of the 46-cm air temperature probe by shading from a pollinator plot.

heights AGL at which Yassin was working and at which much work has been done previously are above ground pesticide applications. A question of how herbicide droplets, such as dicamba, may move or be dispersed when applied during an inversion remains unknown, and future research will be needed.

The data generated here can serve as a resource or guide to assist in identifying times for conducting dispersion experiments and be utilized to validate forecasting models of low-level surface temperature inversions. Currently, through the TIPS website, Missouri pesticide applicators have access to real-time data on air temperatures, wind speed, and relative humidity to assist in decision-making with regard to applying chemicals (http://ag3.agebb.missouri.edu/weather/maps/realTime/ temperature_inversion/ver2/alb_temperature_inversion_ public.png). In addition, multiple weather stations across the Midwestern and midsouthern United States have

TABLE C1. Pearson's correlation coefficients for weather variables during inversion conditions at each site $(2015-17 ; p<0.001)$. Pearsons's correlation coefficients range from -1 to 1 , with a positive number representing a positive correlation and a negative number representing a negative correlation. Values closest to -1 or 1 represent the strongest relationships. Air temperature, relative humidity, dewpoint temperature, and wind speed and direction were all recorded at $305 \mathrm{~cm}$ AGL.

\begin{tabular}{|c|c|c|c|c|c|c|c|c|}
\hline Site & Variable & $\begin{array}{c}\text { Air } \\
\text { temperature }\end{array}$ & $\begin{array}{l}\text { Relative } \\
\text { humidity }\end{array}$ & $\begin{array}{c}\text { Dewpoint } \\
\text { temperature }\end{array}$ & $\begin{array}{l}\text { Wind } \\
\text { speed }\end{array}$ & $\begin{array}{c}\text { Wind } \\
\text { direction }\end{array}$ & $\Delta T$ & Duration \\
\hline \multirow[t]{7}{*}{ Albany } & Air temperature & 1 & -0.14 & 0.82 & 0.19 & 0.02 & -0.07 & -0.11 \\
\hline & Relative humidity & -0.14 & 1 & 0.44 & -0.53 & -0.25 & -0.26 & -0.29 \\
\hline & Dewpoint temperature & 0.82 & 0.44 & 1 & -0.12 & -0.12 & -0.19 & -0.26 \\
\hline & Wind speed & 0.19 & -0.53 & -0.12 & 1 & 0.42 & -0.09 & 0.32 \\
\hline & Wind direction & 0.02 & -0.25 & -0.12 & 0.42 & 1 & -0.07 & 0.13 \\
\hline & $\Delta T$ & -0.07 & -0.26 & -0.19 & -0.09 & -0.07 & 1 & 0.07 \\
\hline & Duration & -0.11 & -0.29 & -0.26 & 0.32 & 0.13 & 0.07 & 1 \\
\hline \multirow[t]{7}{*}{ Columbia } & Air temperature & 1 & 0.14 & 0.87 & -0.05 & -0.06 & -0.26 & -0.18 \\
\hline & Relative humidity & 0.14 & 1 & 0.62 & -0.26 & -0.13 & -0.35 & -0.28 \\
\hline & Dewpoint temperature & 0.87 & 0.62 & 1 & -0.17 & -0.11 & -0.37 & -0.28 \\
\hline & Wind speed & -0.05 & -0.26 & -0.17 & 1 & 0.25 & -0.39 & -0.08 \\
\hline & Wind direction & -0.06 & -0.13 & -0.11 & 0.25 & 1 & -0.06 & -0.01 \\
\hline & $\Delta T$ & -0.26 & -0.35 & -0.37 & -0.39 & -0.06 & 1 & 0.38 \\
\hline & Duration & -0.18 & -0.28 & -0.28 & -0.08 & -0.01 & 0.38 & 1 \\
\hline \multirow[t]{7}{*}{ Hayward } & Air temperature & 1 & -0.01 & 0.82 & -0.16 & 0 & -0.17 & 0.01 \\
\hline & Relative humidity & -0.01 & 1 & 0.55 & -0.38 & -0.18 & -0.18 & 0.02 \\
\hline & Dewpoint temperature & 0.82 & 0.55 & 1 & -0.35 & -0.10 & -0.23 & 0.01 \\
\hline & Wind speed & -0.16 & -0.38 & -0.35 & 1 & 0.35 & -0.30 & 0.09 \\
\hline & Wind direction & 0 & -0.18 & -0.1 & 0.35 & 1 & -0.19 & 0.04 \\
\hline & $\Delta T$ & -0.17 & -0.18 & -0.23 & -0.30 & -0.19 & 1 & -0.13 \\
\hline & Duration & 0.01 & 0.02 & 0.01 & 0.09 & 0.04 & -0.13 & 1 \\
\hline
\end{tabular}


TABLE C2. Pearson's correlation coefficients for weather variables during inversion and noninversion conditions (2015-17; $p<0.001)$. Air temperature, relative humidity, dewpoint temperature, and wind speed and direction were all recorded at $305 \mathrm{~cm}$ AGL.

\begin{tabular}{|c|c|c|c|c|c|c|c|c|}
\hline Condition & Variable & $\begin{array}{c}\text { Air } \\
\text { temperature }\end{array}$ & $\begin{array}{l}\text { Relative } \\
\text { humidity }\end{array}$ & $\begin{array}{c}\text { Dewpoint } \\
\text { temperature }\end{array}$ & $\begin{array}{l}\text { Wind } \\
\text { speed }\end{array}$ & $\begin{array}{c}\text { Wind } \\
\text { direction }\end{array}$ & $\Delta T$ & Duration $^{\mathrm{a}}$ \\
\hline \multirow[t]{7}{*}{ Inversion } & Air temperature & 1 & 0.05 & 0.85 & -0.06 & -0.03 & -0.17 & -0.02 \\
\hline & Relative humidity & 0.05 & 1 & 0.56 & -0.32 & -0.16 & -0.29 & -0.17 \\
\hline & Dewpoint temperature & 0.85 & 0.56 & 1 & -0.22 & -0.11 & -0.28 & -0.10 \\
\hline & Wind speed & -0.06 & -0.32 & -0.22 & 1 & 0.34 & -0.36 & -0.05 \\
\hline & Wind direction & -0.03 & -0.16 & -0.11 & 0.34 & 1 & -0.13 & -0.02 \\
\hline & $\Delta T$ & -0.17 & -0.29 & -0.28 & -0.36 & -0.13 & 1 & 0.22 \\
\hline & Duration & -0.02 & -0.17 & -0.1 & -0.05 & -0.02 & 0.22 & 1 \\
\hline \multirow[t]{7}{*}{ Noninversion } & Air temperature & 1 & -0.30 & 0.72 & -0.06 & -0.02 & -0.22 & - \\
\hline & Relative humidity & -0.30 & 1 & 0.53 & -0.30 & -0.18 & 0.45 & - \\
\hline & Dewpoint temperature & 0.72 & 0.53 & 1 & -0.26 & -0.10 & 0.10 & - \\
\hline & Wind speed & -0.06 & -0.30 & -0.26 & 1 & 0.11 & -0.11 & - \\
\hline & Wind direction & 0.02 & -0.18 & -0.10 & 0.11 & 1 & -0.04 & - \\
\hline & $\Delta T$ & -0.22 & 0.45 & 0.10 & -0.11 & -0.04 & 1 & - \\
\hline & Duration $^{\mathrm{a}}$ & - & - & - & - & - & - & - \\
\hline
\end{tabular}

${ }^{\text {a }}$ The duration category is blank for noninversion conditions because duration of a noninversion event was not defined in this study.

been or are currently being outfitted with similar equipment to generate additional data.

Acknowledgments. This research was funded in part by the Missouri Soybean Merchandising Council projects 17-407-18 and 18-407-19. The authors are especially thankful to John Travlos for systems administrative work with the weather stations and to the University of Missouri Statistics Services for assisting in data organization.

\section{APPENDIX A}

\section{Variability of the Probes and Anemometers over Time}

Air temperatures were recorded every $5 \mathrm{~min}$ at 46 , 168, and $305 \mathrm{~cm}$ above ground level during April, May, June, and July of 2015-17 at Albany, Columbia, and Hayward. Standard deviations for air temperatures at each height are recorded in Figs. A1-A3 to show the similarity among the three air temperature probes. The average 5-min wind speeds from 2015 to 2017 are shown in comparison with 10-yr historical trends of wind speeds at each location in Fig. A4.

\section{APPENDIX B}

\section{Basic Summary Statistics for Inversion Formations at Each Site and Month Studied}

Table B1 displays the basic summary statistics for inversion start times over a 3-yr period.

\section{APPENDIX C}

\section{Exploration of Correlation Relationships among Variables during Inversion and Noninversion Conditions}

For the 3-yr period, Table $\mathrm{C} 1$ gives a list of Pearson's correlation coefficient values for weather variables at each site. Table $\mathrm{C} 2$ gives correlations among weather variables for all sites combined during inversions and when inversions are not present.

\section{REFERENCES}

Akesson, N. B., and W. E. Yates, 1964: Problems relating to application of agricultural chemicals and resulting drift residues. Annu. Rev. Entomol., 9, 285-318, https://doi.org/ 10.1146/annurev.en.09.010164.001441.

Al-Khatib, K., and D. Peterson, 1999: Soybean (Glycine max) response to simulated drift from selected sulfonylurea herbicides, dicamba, glyphosate, and glufosinate. Weed Technol., 13, 264-270, https://doi.org/10.1017/S0890037X00041713.

_, R. Parker, and E. P. Fuerst, 1993: Wine grape response to simulated herbicide drift. Weed Technol., 7, 97-102, https:// doi.org/10.1017/S0890037X00036940.

Allwine, K. J., X. Bian, C. D. Whiteman, and H. W. Thistle, 1997: VALDRIFT - A valley atmospheric dispersion model. J. Appl. Meteor. Climatol., 36, 1076-1087, https://doi.org/10.1175/15200450(1997)036<1076:VAVADM >2.0.CO;2.

Alves, G. S., G. R. Kruger, J. P. A. R. da Cunha, B. C. Vieira, R. S. Henry, A. Obradovic, and M. Grjic, 2017: Spray drift from dicamba and glyphosate applications in a wind tunnel. Weed Technol., 31, 387-395, https://doi.org/10.1017/wet.2017.15.

Baker, D. G., J. W. Enz, and H. J. Paulus, 1969: Frequency, duration, commencement time and intensity of temperature inversions at St. Paul-Minneapolis. J. Appl. Meteor. Climatol., 8, 747-753, https://doi.org/10.1175/1520-0450(1969) $008<0747$ :FDCTAI $>2.0$. CO 2 . 
Battany, M. C., 2012: Vineyard frost protection with upward-blowing wind machines. Agric. For. Meteor., 157, 39-48, https://doi.org/ 10.1016/j.agrformet.2012.01.009.

Beck, H. E., N. E. Zimmerman, T. R. McVicar, N. Vergopolan, A. Berg, and E. F. Wood, 2018: Present and future Köppen Climate Classification maps at 1-km resolution. Nat. Sci. Data, 5, 180214, https://doi.org/10.1038/sdata.2018.214

Behrens, M. R., and Coauthors, 2007: Dicamba resistance: Enlarging and preserving biotechnology-based weed management strategies. Science, 316, 1185-1187, https://doi.org/10.1126/ science. 1141596.

Bird, S. L., D. M. Esterly, and S. G. Perry, 1996: Off-target deposition of pesticides from agriculture aerial spray application. J. Environ. Qual., 25, 1095-1104, https://doi.org/ 10.2134/jeq1996.00472425002500050024x.

Bish, M. D., and K. W. Bradley, 2017: Survey of Missouri pesticide applicator practices, knowledge, and perceptions. Weed Technol., 31, 165-177, https://doi.org/10.1017/wet.2016.27.

Bradley, K. W., 2017a: A final report on dicamba-injured soybean acres. Integrated Pest and Crop Management Newsletter, University of Missouri, https://ipm.missouri.edu/IPCM/2017/ 10/final_report_dicamba_injured_soybean/.

_ 2017b: The dicamba dilemma: Where do we go from here? University of Missouri Crop Management Conf., Columbia, MO, University of Missouri, https://weedscience.missouri.edu/ 2017\%20CMC\%20Bradley.pdf.

— 2018: July 15 Dicamba injury update. Different year, same questions. Integrated Pest and Crop Management Newsletter University of Missouri, https://ipm.missouri.edu/IPCM/ 2018/7/July-15-Dicamba-injury-update-different-year-samequestions/.

Creech, C. F., R. S. Henry, B. K. Fritz, and G. R. Krueger, 2015: Influence of herbicide active ingredient, nozzle type, orifice size, spray pressure, and carrier volume rate on spray droplet size characteristics. Weed Technol., 29, 298-310, https://doi.org/ 10.1614/WT-D-14-00049.1.

EPA, 2017a: Engenia specimen herbicide product label. BASF and EPA Office of Chemical Safety Doc., 30 pp., https://www3.epa.gov/ pesticides/chem_search/ppls/007969-00345-20171012.pdf.

_- 2017b: Xtendimax with VaporGrip technology herbicide product label. Monsanto Company and EPA Office of Chemical Safety Doc., 56 pp., https://www3.epa.gov/pesticides/ chem_search/ppls/000524-00617-20181101.pdf.

Enz, J. W., V. Hofman, and A. Thostenson, 2017: Air temperature inversions: Causes, characteristics, and potential effects on pesticide spray drift. North Dakota State University Extension Service Publ. AE1705, 16 pp., https://www.ag.ndsu.edu/publications/ crops/air-temperature-inversions-causes-characteristics-andpotential-effects-on-pesticide-spray-drift/ae1705.pdf.

Everitt, J. D., and J. W. Keeling, 2009: Cotton growth and yield response to simulated 2,4-D and dicamba drift. Weed Technol., 23, 503-506, https://doi.org/10.1614/WT-08-061.1.

Ferguson, S. A., R. L. Collins, J , Ruthford, and M. Fukuda, 2003: Vertical distribution of nighttime smoke following a wildland biomass fire in boreal Alaska. J. Geophys. Res., 108, 4743, https://doi.org/10.1029/2002JD003324

Finn, D., K. L. Clawson, R. G. Carter, J. D. Rich, and K. J. Allwine, 2008: Plume dispersion anomalies in a nocturnal urban boundary layer in complex terrain. J. Appl. Meteor. Climatol., 47, 2857-2878, https://doi.org/10.1175/2008JAMC1864.1.

Fritz, B. K., W. C. Hoffman, Y. Lan, S. J. Thomson, and Y. Huang, 2008: Low-level atmospheric temperature inversions and atmospheric stability: Characteristics and impacts on agricultural applications. Agric. Eng. Int.: CIGR Ejournal, X, PM 08 001, http://www.cigrjournal.org/index.php/Ejounral/article/download/ $1234 / 1091$.

Guinan, P., 2015a: June 2015 weather and its impacts on Missouri. Climate Missouri News, University of Missouri, http://climate.missouri.edu/news/arc/jul2015.php.

—_, 2015b: July 2015 weather and its impacts on Missouri. Climate Missouri News, University of Missouri, http:// climate.missouri.edu/news/arc/aug2015a.php.

Hall, B. L., and Coauthors, 2015: A community frost/freeze susceptibility operational guidance tool. J. Oper. Meteor., 3, 21-29, https://doi.org/10.15191/nwajom.2015.0303.

Holzworth, G. C., 1967: Mixing depths, wind speeds and air pollution potential for selected locations in the United States. J. Appl. Meteor. Climatol., 6, 1039-1044, https://doi.org/10.1175/ 1520-0450(1967)006<1039:MDWSAA > 2.0.CO;2.

Hosler, C. R., 1961: Low-level inversion frequency in the contiguous United States. Mon. Wea. Rev., 89, 319-339, https://doi.org/ 10.1175/1520-0493(1961)089<0319:LIFITC > 2.0.CO;2.

Hunt, E. D., J. B. Basara, and C. R. Morgan, 2007: Significant inversions and rapid in situ cooling at a well-sited Oklahoma Mesonet station. J. Appl. Meteor. Climatol., 46, 353-367, https://doi.org/10.1175/JAM2467.1.

Janhall, S., 2015: Review on urban vegetation and particle air pollution-Deposition and dispersion. Atmos. Environ., 105, 130-137, https://doi.org/10.1016/j.atmosenv.2015.01.052.

Jones, G. T., J. K. Norsworthy, and T. Barber, 2019: Off-target movement of dicglycolamine dicamba to non-dicamba soybean using practices to minimize primary drift. Weed Technol., 33, 24-40, https://doi.org/10.1017/wet.2018.90.

Massey, R., and P. Guinan, 2011: Missouri agricultural weather wind information and resources. University of Missouri, accessed 17 January 2019, http://agebb.missouri.edu/weather/ windroses/.

Matuszko, D., 2012: Influence of the extent of and genera of cloud cover on solar radiation intensity. Int. J. Climatol., 32, 24032414, https://doi.org/10.1002/joc.2432.

McPherson, R. A., and Coauthors, 2007: Statewide monitoring of the mesoscale environment: A technical update on the Oklahoma Mesonet. J. Atmos. Oceanic Technol., 24, 301-321, https:// doi.org/10.1175/JTECH1976.1.

Monahan, A. H., T. M. Rees, and Y. He, 2015: Multiple regimes of wind, stratification, and turbulence in the stable boundary layer. J. Atmos. Sci., 72, 3178-3198, https://doi.org/10.1175/ JAS-D-14-0311.1.

Pfleeger, T. G., D. Olszyk, C. A. Burdic, G. King, J. Kern, and J. Fletcher, 2006: Using a geographic information system to identify areas with potential for off-target pesticide exposure. Environ. Toxicol. Chem., 25, 2250-2259, https://doi.org/10.1897/05-281R.1.

Poulos, G. S., and Coauthors, 2002: CASES-99: A comprehensive investigation of the stable nocturnal boundary layer. Bull. Amer. Meteor. Soc., 83, 555-582, https://doi.org/10.1175/15200477(2002)083<0555:CACIOT >2.3.CO;2.

Ribeiro, A. C., J. Paulo De Melo-Abreu, and R. L. Snyder, 2006: Apple orchard frost protection with wind machine operation. Agric. For. Meteor., 141, 71-81, https://doi.org/10.1016/ j.agrformet.2006.08.019.

Solomon, C. B., and K. W. Bradley, 2014: Influence of application timings and sublethal rates of synthetic auxin herbicides on soybean. Weed Technol., 28, 454-464, https://doi.org/10.1614/ WT-D-13-00145.1.

Stieger, J., I. Bamberger, N. Buchmann, and W. Eugster, 2015: Validation of farm-scale methane emissions using nocturnal 
boundary layer budgets. Atmos. Chem. Phys., 15, 1405514 069, https://doi.org/10.5194/acp-15-14055-2015.

Stull, R. B., 1988: An Introduction to Boundary Layer Meteorology. Kluwer Academic, 666 pp.

Sun, J., L. Mahrt, R. M. Banta, and Y. L. Pichugina, 2012: Turbulence regimes and turbulence intermittency in the stable boundary layer during CASES-99. J. Atmos. Sci., 69, 338-351, https://doi.org/10.1175/JAS-D-11-082.1.

Thistle, H. W., J. A. S. Bonds, G. J. Kees, and B. K. Fritz, 2017: Evaluation of spray drift from backpack and UTV spraying. Trans. ASABE, 60, 41-50, https://doi.org/10.13031/trans.11990.

Thom, R. H., and J. H. Wilson, 1983: The natural divisions of Missouri. Nat. Areas J., 3, 44-51.

University of Missouri Commercial Agriculture, 2019: Missouri Historical Agricultural Weather Database. Subsets used: April-July 2015, April-July 2016, and April-July 2017, accessed 17 January 2019, http://agebb.missouri.edu/weather/history/index.asp.

USDA, 1981: Land resource regions and major land resource areas of the United States. Soil Conservation Service Agriculture Handbook 296, 161 pp., https://naldc.nal.usda.gov/download/ CAT82777198/PDF.

_- 2012: 2012 Census data of agriculture-county data, table 1, county summary highlights. National Agricultural Statistics Service, accessed 1 March 2018, https://www.agcensus.usda.gov/ Publications/2012/Full_Report/Volume_1,_Chapter_2_County_ Level/Missouri/st29_2_001_001.pdf.

_ 2015a: Determination of non-regulated status for Monsanto Company MON 88701 cotton. Animal and Plant Health Inspection Service Doc., 3 pp., https://www.aphis.usda.gov/brs/ aphisdocs/12_18501p_det.pdf.

_ 2015b: Determination of non-regulated status for Monsanto Company MON 88701 soybean. Animal and Plant Health
Inspection Service Doc., 3 pp., https://www.aphis.usda.gov/ brs/aphisdocs/10_18801p_det.pdf.

_- 2015c: Determination of non-regulated status for Dow AgroSciences DAS-8190-7 cotton. Animal and Plant Health Inspection Service Doc., 3 pp., https://www.aphis.usda.gov/ brs/aphisdocs/13_26201p_pdet.pdf.

_ 2017: Web soil survey. Natural Resources Conservation Service, accessed 17 January 2019, https://websoilsurvey.sc.egov.usda.gov/.

Van de Wiel, B. J. H., and Coauthors, 2017: Regime transitions in near-surface temperature inversions: A conceptual model. J. Atmos. Sci., 74, 1057-1073, https://doi.org/10.1175/JAS-D16-0180.1.

VanGessel, M. J., and Q. R. Johnson, 2005: Evaluating drift control agents to reduce short distance movement and effect on herbicide performance. Weed Technol., 19, 78-85, https:// doi.org/10.1614/WT-03-248R.

van Hooijdonk, I., and Coauthors, 2017: Near surface temperature inversion growth rate during the onset of the stable boundary layer. J. Atmos. Sci., 74, 3433-3449, https://doi.org/10.1175/ JAS-D-17-0084.1.

Yassin, M. F., L. A. Al-Shatti, and M. S. Al Rashidi, 2018: Assessment of the atmospheric mixing layer height and its effects on pollutant dispersion. Environ. Monit. Assess., 190, 372, https://doi.org/10.1007/s10661-018-6737-9.

Yates, W. E., N. B. Akesson, and H. H. Coutts, 1967: Drift hazards related to ultra-low-volume and dilute sprays by agricultural aircraft. Trans. ASAE, 10, 628-632, https://doi.org/10.13031/ 2013.39747.

__ _ — - and R. E. Cowden, 1974: Criteria for minimizing drift residues on crops downwind from aerial applications. Trans. ASAE, 17, 637-632, https://doi.org/10.13031/ 2013.36925. 